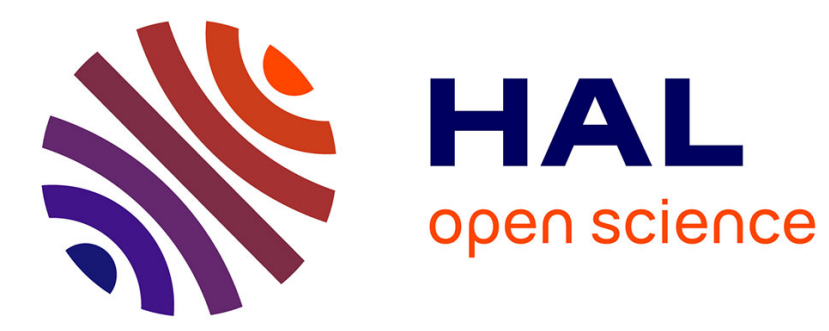

\title{
Using deformable surfaces to segment 3-D images and infer differential structures
}

\author{
Isaac Cohen, Laurent D. Cohen, Nicholas Ayache
}

\section{To cite this version:}

Isaac Cohen, Laurent D. Cohen, Nicholas Ayache. Using deformable surfaces to segment 3-D images and infer differential structures. CVGIP: Image Understanding, 1992, 56 (2), pp.242-263. 10.1016/1049-9660(92)90041-Z . inria-00615537

\section{HAL Id: inria-00615537 \\ https://hal.inria.fr/inria-00615537}

Submitted on 19 Aug 2011

HAL is a multi-disciplinary open access archive for the deposit and dissemination of scientific research documents, whether they are published or not. The documents may come from teaching and research institutions in France or abroad, or from public or private research centers.
L'archive ouverte pluridisciplinaire $\mathbf{H A L}$, est destinée au dépôt et à la diffusion de documents scientifiques de niveau recherche, publiés ou non, émanant des établissements d'enseignement et de recherche français ou étrangers, des laboratoires publics ou privés. 


\title{
Using Deformable Surfaces to Segment 3-D Images and Infer Differential Structures
}

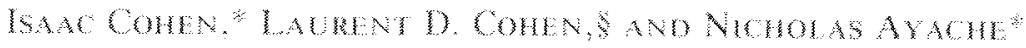

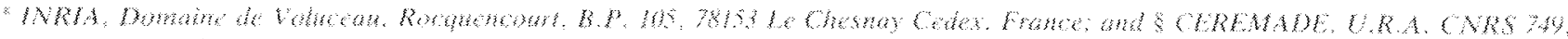

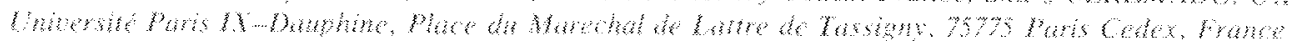

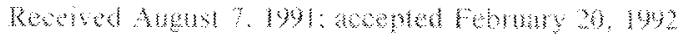

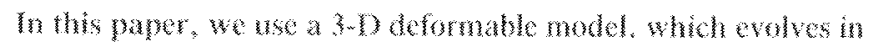

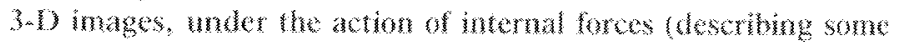

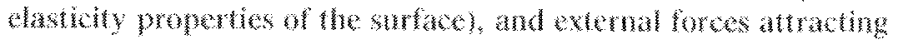

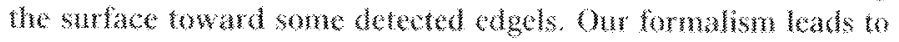
the minimation at an energy which is expresed as a functonal.

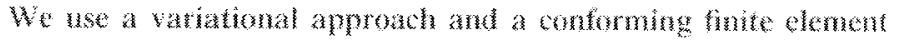

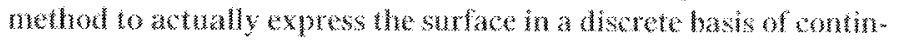
wous fuxthons. The leads to reduced computatonal complexity

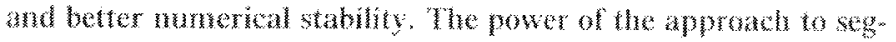
mentim 3-D inages is demonstated by a set of experimental

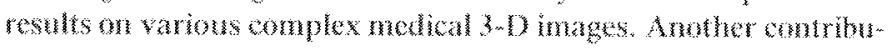

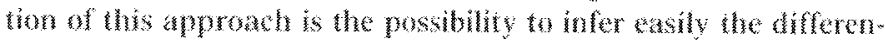

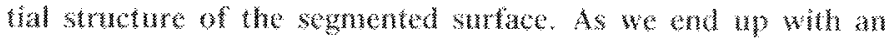

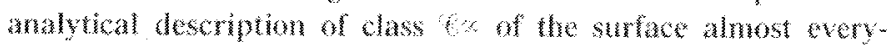

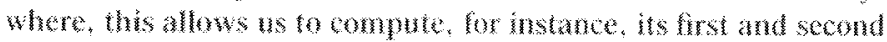
fundamental forms. Fom this, bue can extract a curvature primat

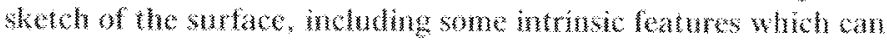

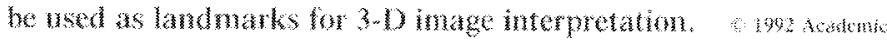
prese the

\section{NTRODUCTON}

We propose atomable $3 \mathrm{D}$ shape model which an be used 10 extract roble surfaces in $3 \mathrm{n}$ images and inter a diferental structure on thew.

Ysually, 3mbimares are givenas as of intenwity pox.

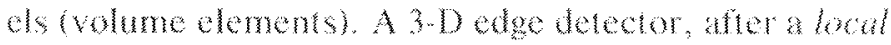
mage analysis 127,36$]$. phovides a set of 3 bedgels fodge dements). These agels cin be consthere as the trae of a cerain number of suraces. One is hen confronted wh a dual problem:

1. Soled edgels belonging the sume sunce trace: this is the sementatun probm.

2. Recover an connous and dferentable destiption

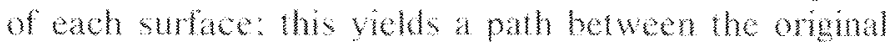
sparse discrete datand the abily lo compute a diferen-

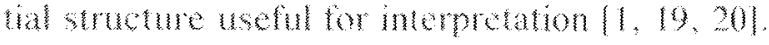

Both questons were analyed by sander and zucker

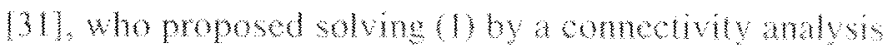

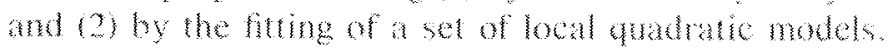

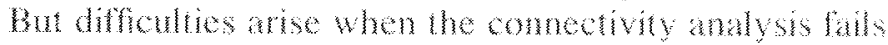

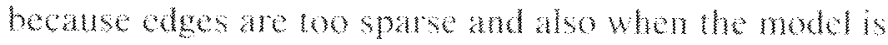
too local to rehably aeserbe a complex shape.

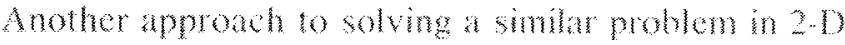
consists of hrotucine an active dofomable mokel [2al. Which solves the semonation problem (l) assuming that an inial estimate is provided an inial sownon migh be

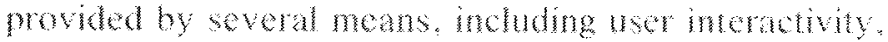
whoh is usualy encuraged in medied applications and the interpotation problem (2) when the curve is a pressed in a basis of conthuous functions $[14,28]$. Such models

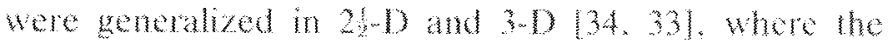
deformble surbere is evolume under the hroes com pued on a $2-1$ image on as of 20 images.

In connas wh the methots of recostruction based

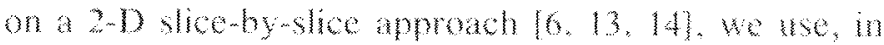
this paper a ${ }^{2}-\mathrm{D}$ dofomable model.

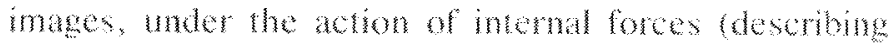

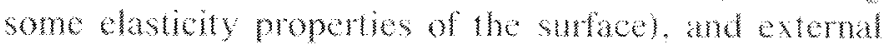
forces attracting the surace lowar some detected digels. This formalism leats to the mimization of an

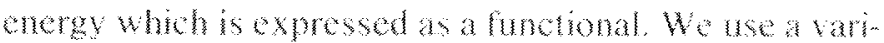

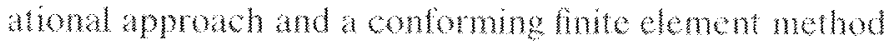
wexpess the sutace in a discrete basin of contunous functoms. This method allows us 10 perfom an "adap tive sublvion" of the pametration tomain whout ahing nodal points and consequenly whoul increang the size of the linear system we solve. This lats fo re ducel computhomal complexity and beter mumbical

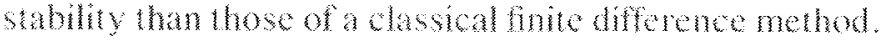

The power of the approch to sement 3 is images is demonerated by a set oxpermental resuls on comm plex medical 3u minges (see aso 111$)$ )

Another contribution of this aptroth is the whity to easty infer the diffrental structue of the segmented

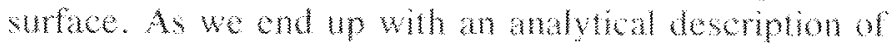

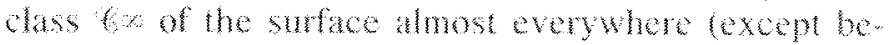

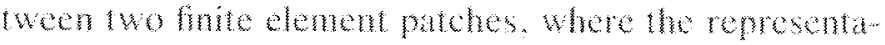




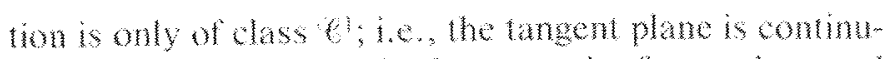
oxs), we can comple for husance, is first and second fundamental foms [17]. Thum this. one can extact a convatue primal sketch of the sutace [30, 8], including

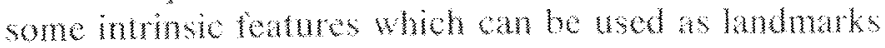
for 30 image interpretation $12,19 \%$.

Last but not least, a careful amysis of our externat

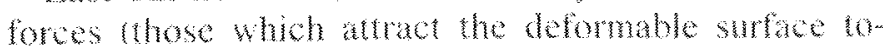
ward the edges) stows some intrgungumections wh the propertes of minimal sufacs: if the deformale surface is animal surace lie. a sutace whose mean curvature is everyluere zero, then it satisfes atso the definion of an edge sumbe.

The paper is organded as follows: We hrst define the 3D detomable model (Secton 2 ) and then give an appro priate extemal fore (Sector 3 ) and its relationship with 3 D coge poins (Secton 4). We show then how to solve this mimizaton problem by a confoming hine element method (section 5 ) and give a conect choce of the regulariation parmeters (Sechon 0 ). An algorihmo com plexily comparison between the combrming finte elo ment method and the hinte docence method is given in Serton 7 . Section 8 indeste how to infer the biferential stucture of the 3-1) images from the obtained suftac. Fually section 9 descrbes a set of expormental resuls on synhorical and complex mencal 30 images.

\section{ONERGYMNMUZNG SURACLS}

A 3-D image is given by a set of intensivy wals, an as a set of sucessive $2 \mathrm{D}$ choss sectons, In out hrst work 13. 4) we processed 3 D images as a set of sucessives

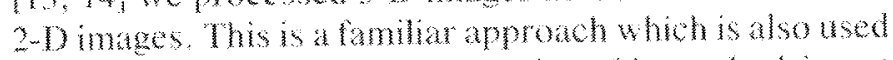
m tackmp mothots $[3,12,21]$, but the method is not efrotive and camot ake into accomm the spatal homo geneity of the data. In the following we conster the 3 d image data as a set of parel and the bundates of a 34 imase are descrbed by a set sumaces.

A dofomable surace nodel alows us be chaterize

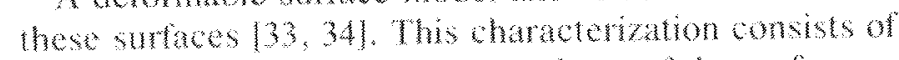
determing the location and the shepe of the surface.

ly the following we restat auselves to paramererized sulaces, snce any 3 D surace has a local parameterizin tion $11 \%$.

This modes is deflned by a space of admissble deform

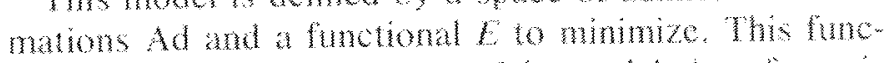

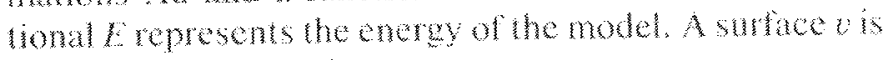
delned by the mapping

$$
\begin{aligned}
& M=\|1,\| \times M, \| \rightarrow R^{3} \\
& (s, n), m(s, n)=(n(s, n), y(s, n, \pi(s, n)
\end{aligned}
$$

and the associatod energy is aven by

$$
\begin{aligned}
& \angle: A n \rightarrow K
\end{aligned}
$$

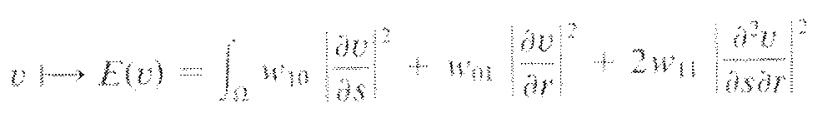

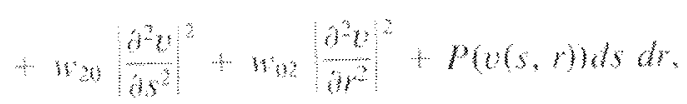

Where $P$ is the potental assoctated with the externat forces. The externa hores reter to the fores which atbw the surace to lowize the inage atubutes. So, if we

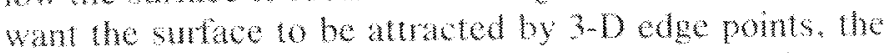
potental is expressed in terms of a 3 d gradient image. The witerna foros acting on the shane of the surtace depend ow the coefferents wach that the elsticity is

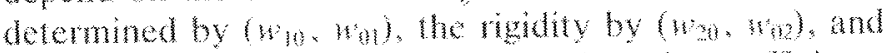
the resistance to wist by wh. Therefore the coefficients wetemme the mechanca properties of the surfac. whese cofficionts are also called reguatization parme. less. We an atso constan the sulace structure by adjusting boundary conditions for instance, wereate a cylinter or a torus?.

A local minmum of 0 satses the assochted Eulerm Lagrange equation

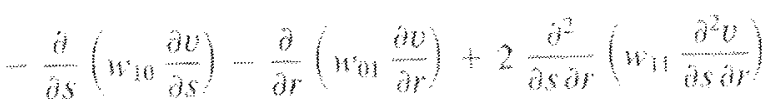

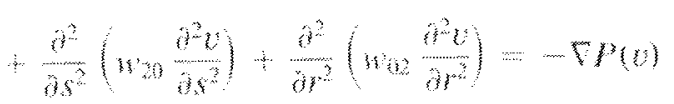

$$
\begin{aligned}
& \text { - boundary conditons. }
\end{aligned}
$$

Whoh represents he necessary contion or a minmum (E) $=0$. A solution of la (1) can be seven as ench

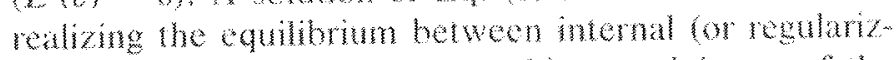
mag) and extemat forces or raching a minumu of the energy

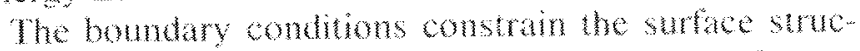

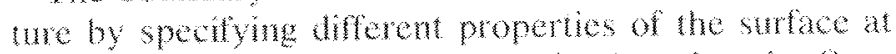

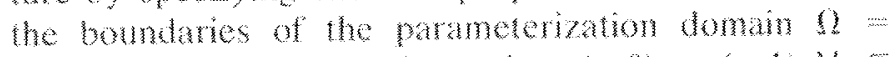

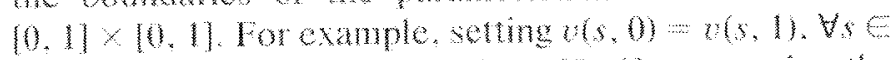

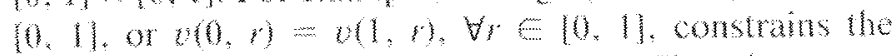

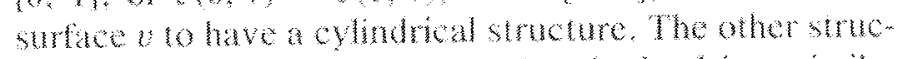

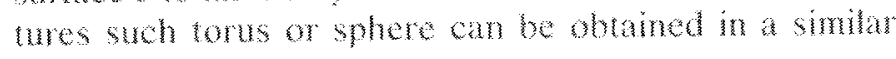
way.

Since the energy function is not cowex, there may be many local minima of $t$. The culormatange squaton

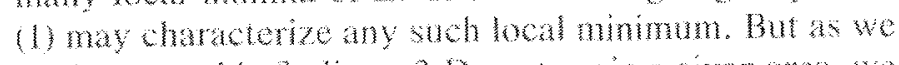
are interested in hnding a 3 -b comowe in a given area, we assume in act that we have a rough prop estmation of the surfoce. This extmate is used as intwata for the

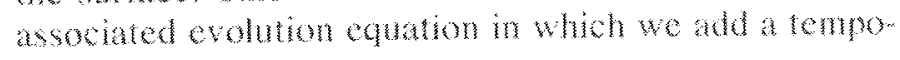
ral parmeter 


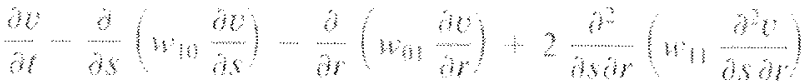

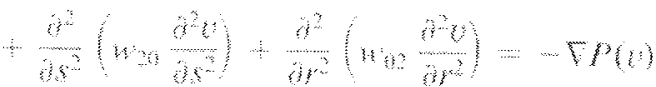

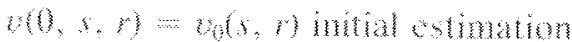

thondary coudions.

A shlution the sath problen is loum when the solu

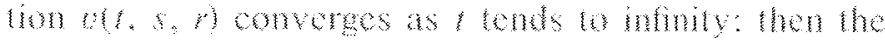

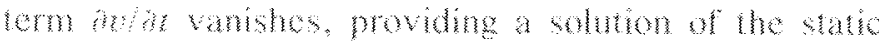
publem

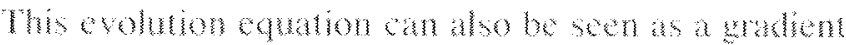

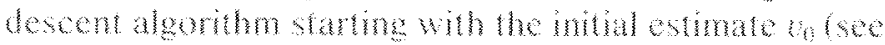
section 5 , 3 .

\section{MEGNWG THE WTLNTAL}

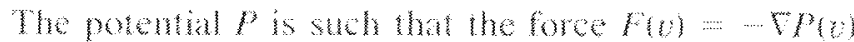
must atmat the surace the imese antwutes that we loking for Our mam goal is the extrotion of "goot" edge points fie. to be whe to remove suntous

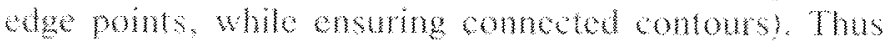
the suface mut he atracted by atge ponts and min. mise he energy

$$
E_{m}=\iint_{n} m(n, w) d s d r
$$

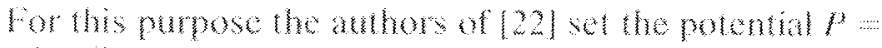

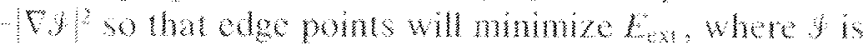

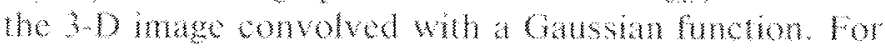

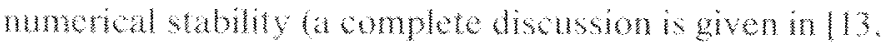
14) we nomatize the foree

$$
f(v)=-\xi^{\frac{w}{b !}}
$$

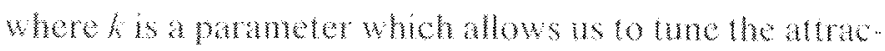

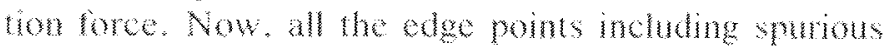

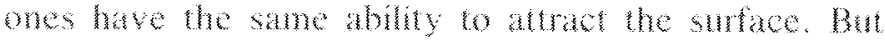
shumous mints generly fom small comected compo nens in 3 - Dmages. conseguculy, when the suraceon verges toward the real contours, all these poms thest at

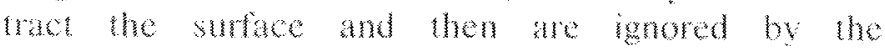
remariation wewt of the algothm.

Another way to make the edge points atract the sum

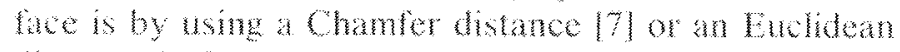
wistace 116 mage. The distance muge is obtand by computing at ach image poin (raen the distace to the meares edge point these poins are obaned by acul abe detecton. These distanes allow us to compute at sach image point the atraston fores to the nearest adsels. This fore can be compued in diterent says,

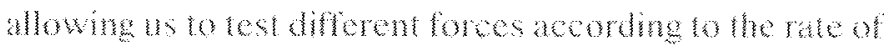
convergenes of the algorithm. Tor instance.

$$
P(t)+n)=-e^{-4 t a s m}
$$

produces a she comergenes wheress

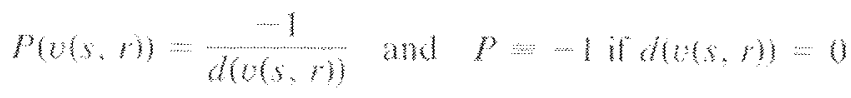

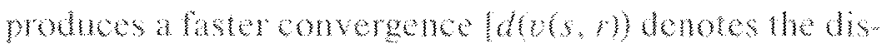

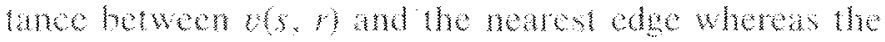

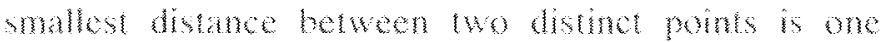
pixel. The use of such atmotion potendaks detaled in 19

\section{MINMULNG SURHACES ANO SD MMAE EDGE POINT,}

In the prevous secton we shomed how to choose cor.

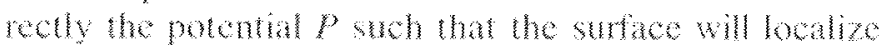
acumtely the doe poins. Here we comment an the vationship between the sutace minizing the mergy of extemal hoes $t$ and 30 edge pons. This is a generalization to 3 . D suraces of the result given by $F$ and Lectere $[18]$ for $2 \mathrm{~d}$ arves. We use the following

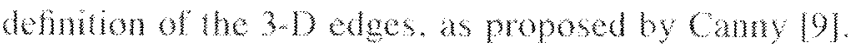

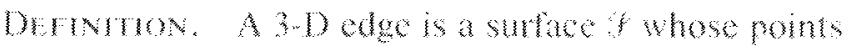

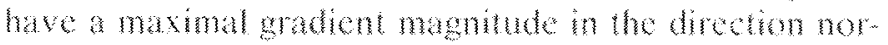

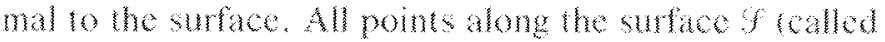
Cumy"s edge points) satisfy

$$
\frac{d P(x(s, r))}{d N(x(s, H)}=0
$$

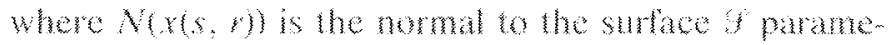
terized by the application $x, y$ and $g$ denotes be mage

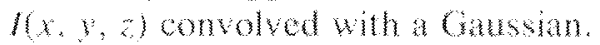

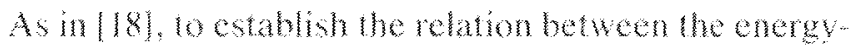
miniming suraces and the dehition. let us fetine the energy associtat to the extermat forces as

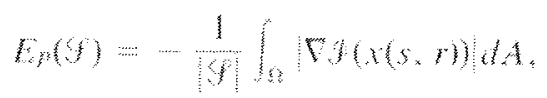

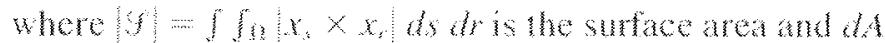

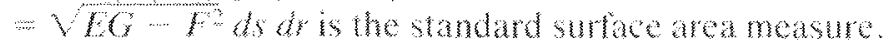

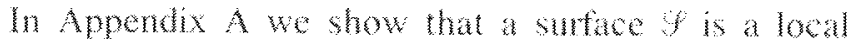
minmmon of $E_{z}$, wh respect 10 infintesimal defma tion, if 


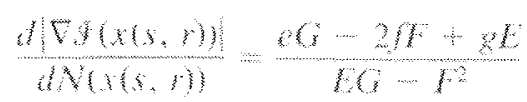

$$
\begin{aligned}
& \left.(x, s, n)-\frac{1}{4)}(F,(x), n) d A\right)
\end{aligned}
$$

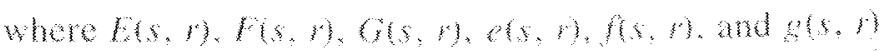

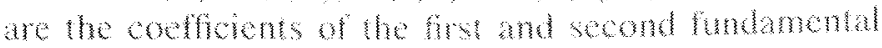

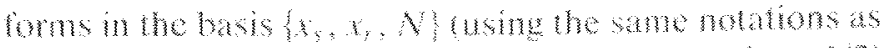

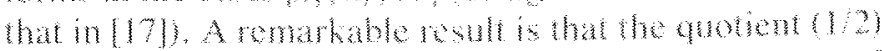

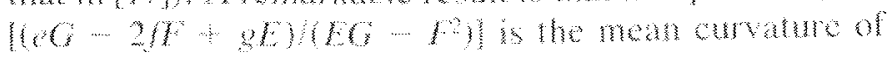
he sulace 9

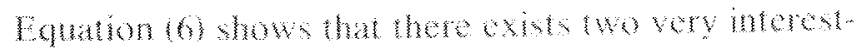
ing spentat asos:

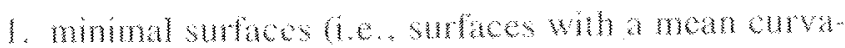
we whon is every were zoro and

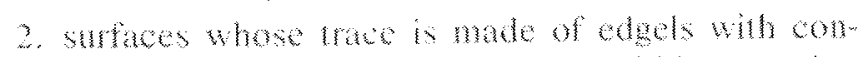

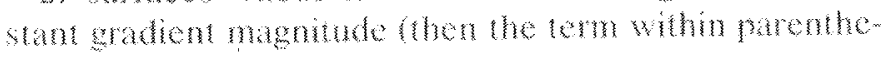
sos in fa, (6) monses)

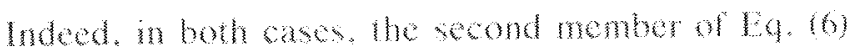
vanisus forero, whon means thet Camy's coge poins

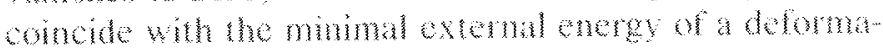
be molel.

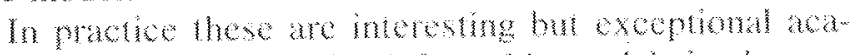

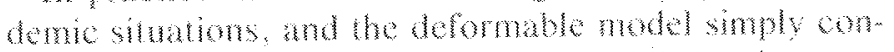

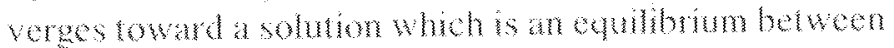
the appled exterm hos comesponding to the enery

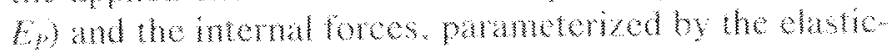
in cochowents $n$.

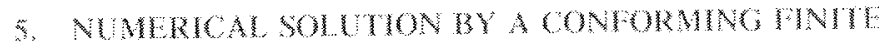 ELENENT WETON}

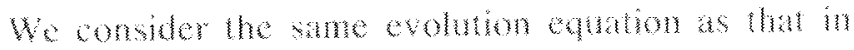
section 2 :

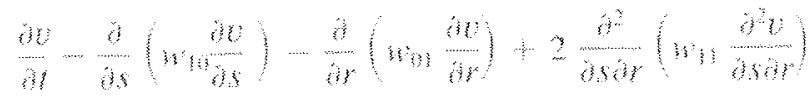

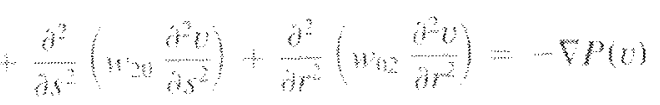

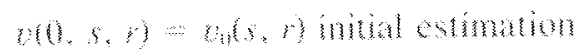

houndary conumbers.

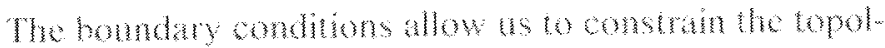

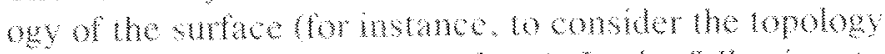

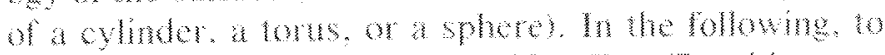

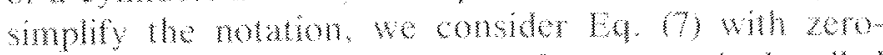

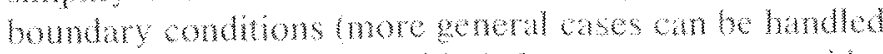

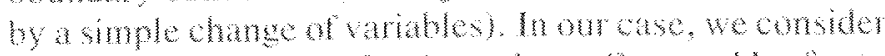

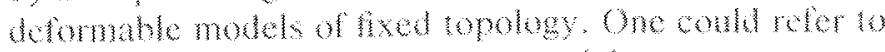

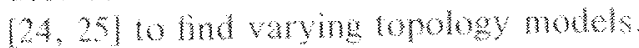

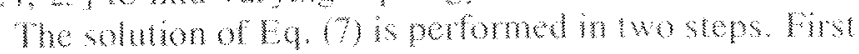

we solse the sato problem (1) whth a confom min

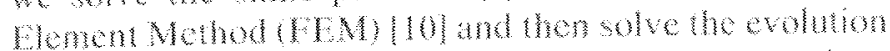

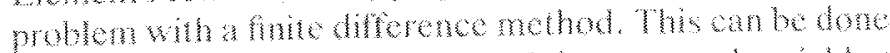

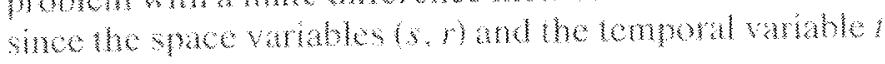
are muspendent

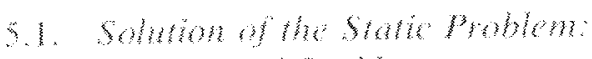

\section{The wathinat Problen}

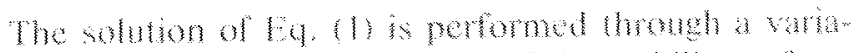

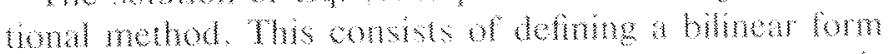

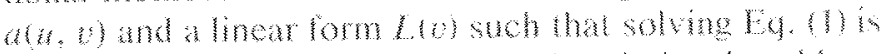

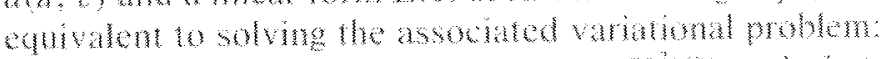

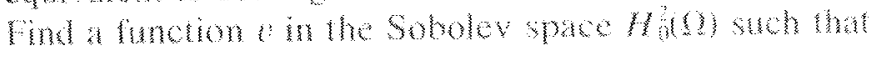

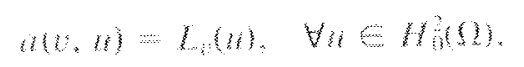

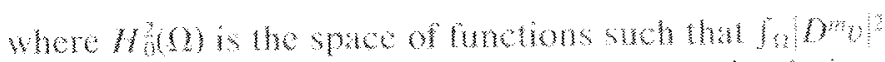

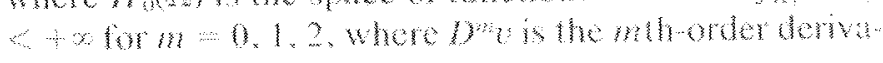

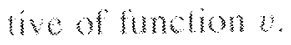

One can easily remark that solute the wathond

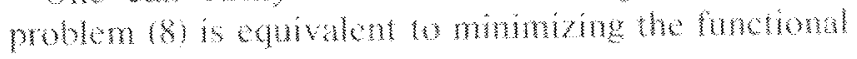

$$
y(n)=1, n, n)-1,(n)
$$

The by seling

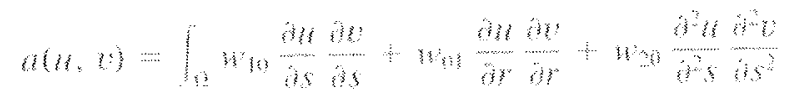

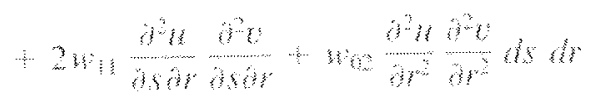

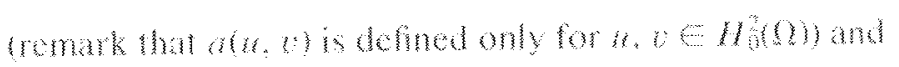

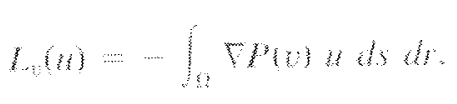

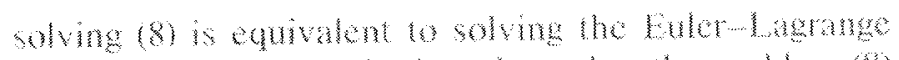

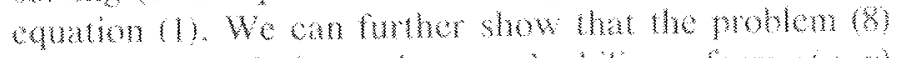

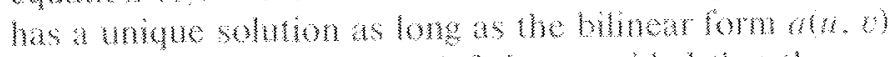
is symmotro and postre definte proved that the pa

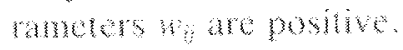

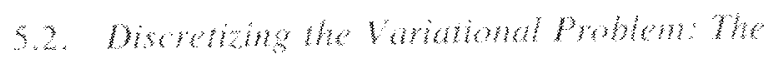 Conforming fN}

So far, we hase dealt wh the conthums form of the vatution probom to show the extence and the

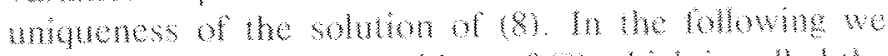

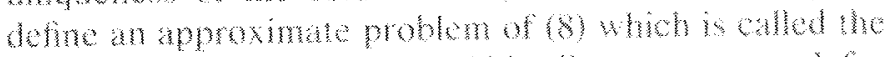

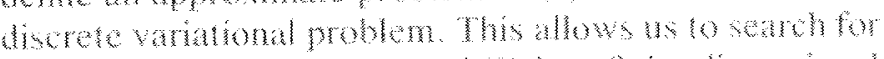

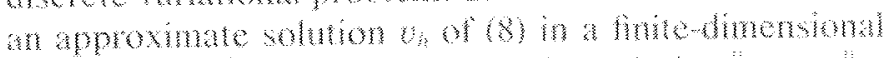

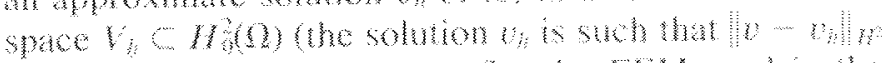

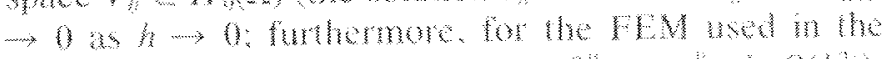

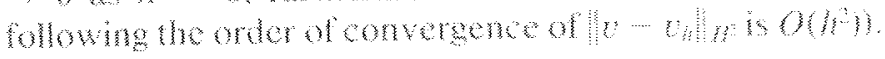




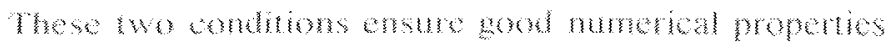
of the discretraton solemes and atre the bas of the

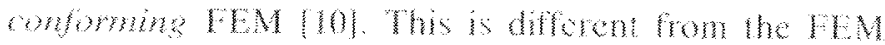

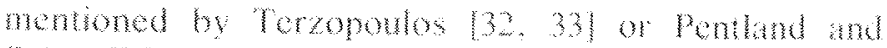

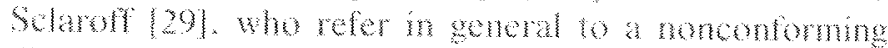

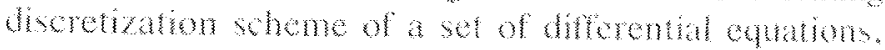
such as thas of hathe 14 for insmoe.

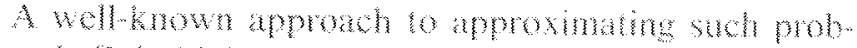

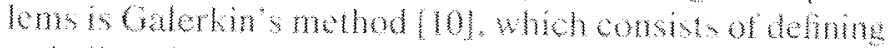

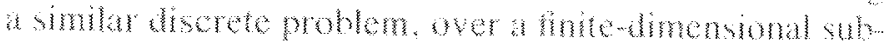

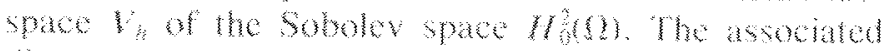
Whate probmen $(\mathrm{O})$ is

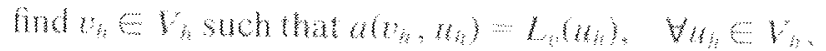

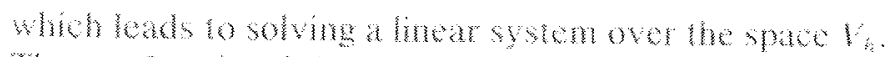

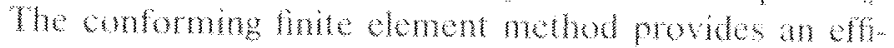

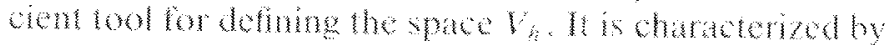
three uspects:

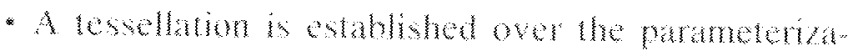
tom set $1=\mid 0,1) \times 10,11$.

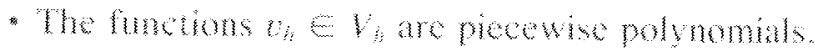

- There exists a bus in the spoce $V_{h}$ whose funcions have samil suppont

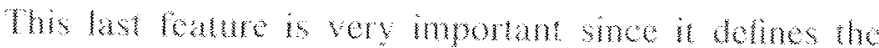
chucture of the linear system that we solec. Choming funclins with small suppon indues a very sparse lnear

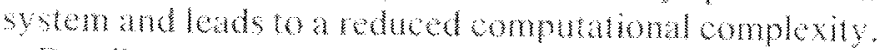

Detals on the tesselation of the doman a and the

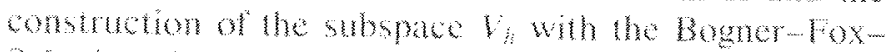

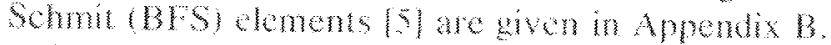
\{it?

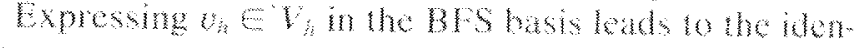

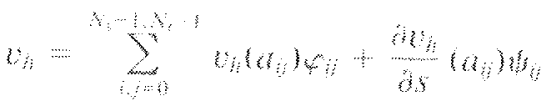

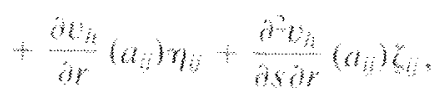

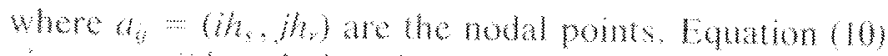

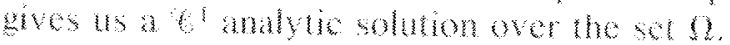

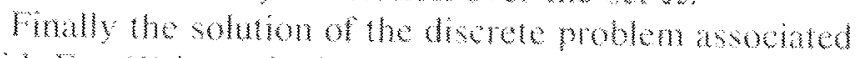

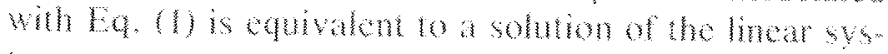
tem

$$
1 \cdot Y=1
$$

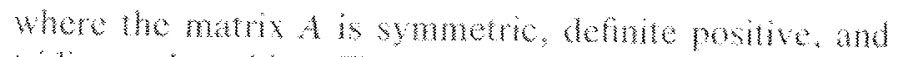

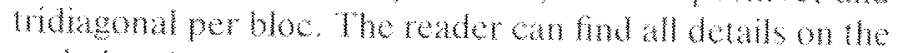
whand problem and lincar sysom (II) in Appen dix $B$.

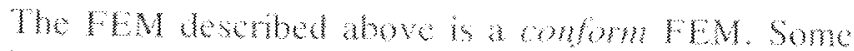

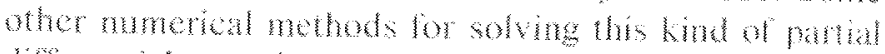

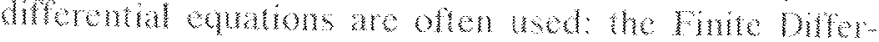

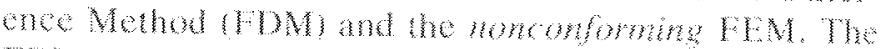

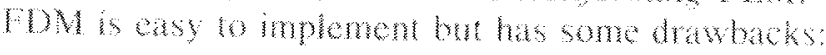

* the solutim is known only al he mold ponts and

* the applod forces are raken into accoum only at nowa poms and consequenty, owe must has a large muber of nod points to compue accumely the anpled

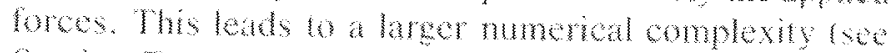
servon?

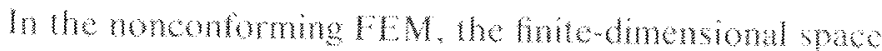

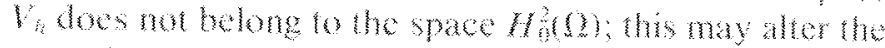
moothess of the sombon. These mothods bo not popa. gute the stress and the strin coneoly by and do no

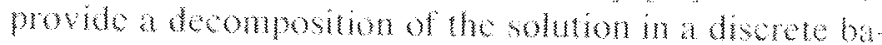
sis of contmous fumcions.

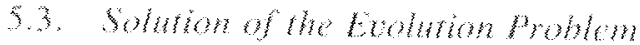

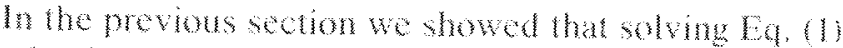
can be bone by solving linear system $A \cdot V=L$. conse. quatly the discrete tom of the evoluton of $\mathrm{Eq}$ (7) is

$$
\frac{n}{n !}+A \cdot Y+\cdots
$$

Whis equation is solvat by an implot steme.

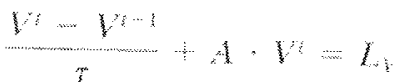

$$
\begin{aligned}
& \text { Yo minal estuman. }
\end{aligned}
$$

Where is the lime step.

This scheme is anfloult to solve suce the term $t$ is complex. Thus whe hechsen an mphit scheme for and an explicit schene tor the rowes 6 . This lads to the solutun of the linear sysum

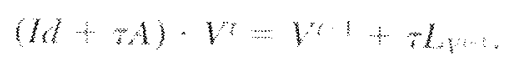

mally to hat a soluton to ra. (T) we must solve the

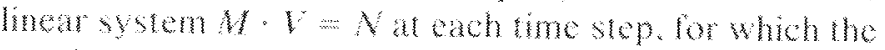

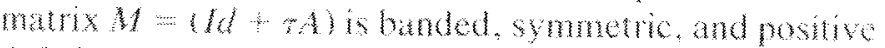

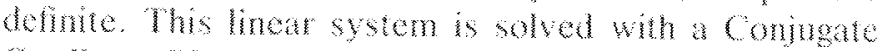

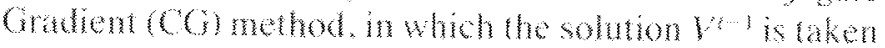

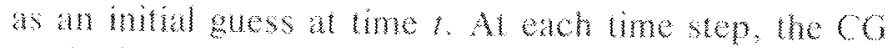

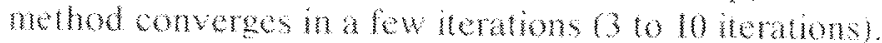

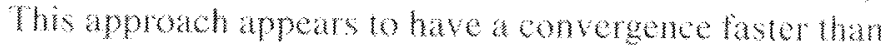
that of a chokew twowhaton and take less memory tor storays. 


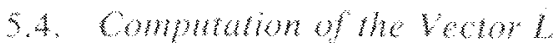

The vector 1 , mere

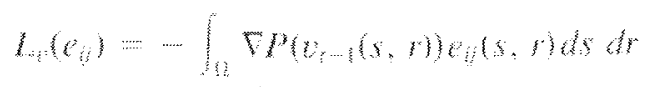

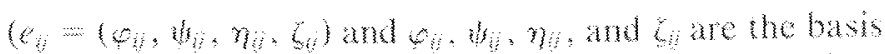
funchons of the BPS element, revesents the contriba

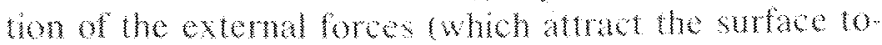

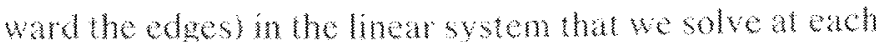
Heraton. Thus, the more we wolght the potential the more accure the result and the aster the comergence.

since he potental $P$ is known only an integer values (discrete image data) we must compule the $L$ (e) with a numerical integration. Conseguenty we compute $F p$ at any pont $(x, y, z) \in k^{3}$ by a rimean imerpohton of its cont neighbors.

To take into acoum all the contributons of the exter nal tores, we molited the numencal inegration fomula such that every mage poin in the set $v(1-1) h_{5}$.

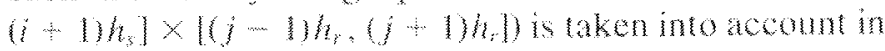
the computation of exh term $l_{*}\left(x_{i}\right)$. Let $h\left(x_{0} r\right)$

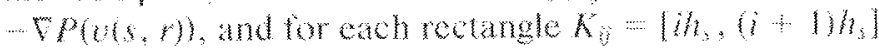
$\times\left[h_{n},\left(y+1 h_{h}\right]\right.$

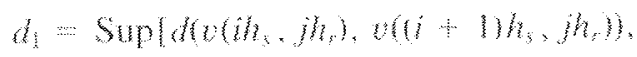

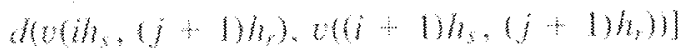

and

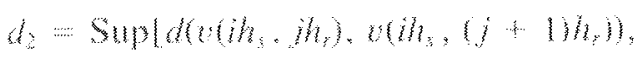

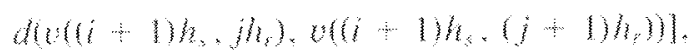

where $d \cdot, \cdot$ denotes the 3.D Euduean distance. Thus

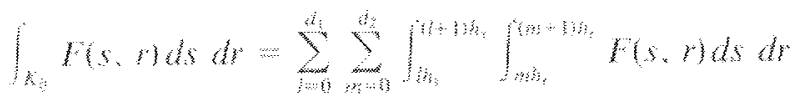

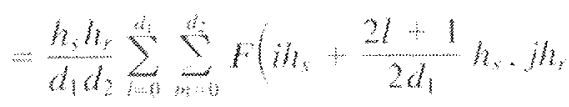

$$
\begin{aligned}
& \left.+\frac{2 m+1}{3 b} h_{n}\right)
\end{aligned}
$$

This molnod alows sion of the rectangl $K_{4}$ whout adding nodal poins and conscumenty without increasing the size of the lineat sysem that wo sole. This method signicanly reduces

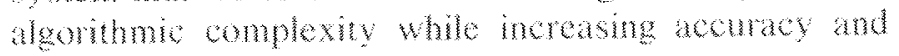
contergence sped

\section{REGUARLATION ARAMTERS}

The easticity and rigity coenciens wy plat an in portan role the converence process of the surace

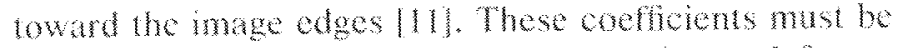
chosen in a comed way such that the inemat forces generated by the endry

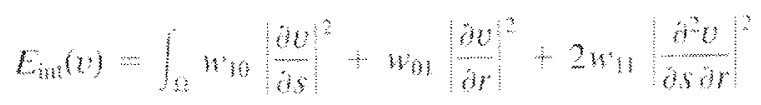

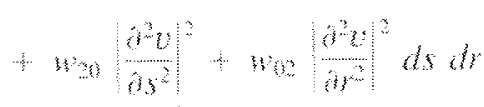

have the same magniude as the extrmat hees $F(b)$. In this case antmum of the energy $L$ will be a trade-ol between the intermal and axtemal energy, and the ofm lamed surface will hit the edge poins while being smowh and regular. If the internat chergy is preponderant the surace will tew to collapse on itself withou detecting image edges. Whereas if the extornal energy pretominates, the surace wil converge along the image edges with any degree of smoothing

To chsure that both intemal and exernal energy have the same order of manutude we have found if suffocon to choose the coefficuts wis such that he linear system of $\mathrm{fq}$. (7) is well condioned. This lats to

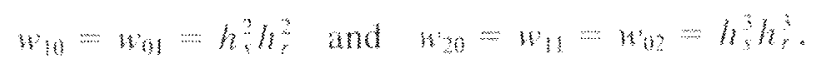

where $h_{3}$ and $h$, are the discretration step of $n$

We set $w_{k}=w_{0}$ and $w_{3}=$ wn whe sine the 30

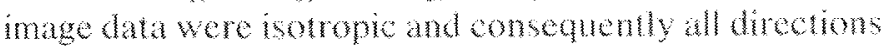
have the same weight.

\section{NUMERICAL COMPLEXYY}

In the following we compare the algorimbio complex-

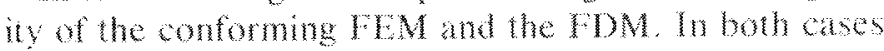
the discretzaton of the evolution equation (2) leats to the sulutor of the lnear system (13), bu the muter of unknowns is diferent. Whe contorming FEM at woh

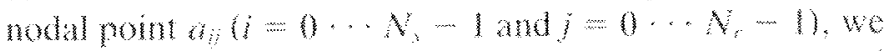

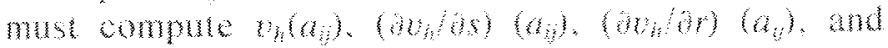

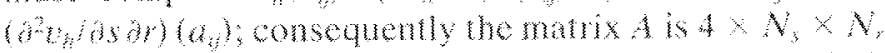

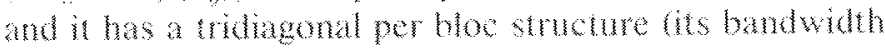
is 2 , . I : sec Appendix B.3.

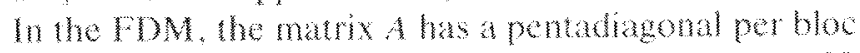

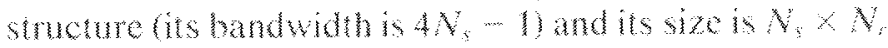

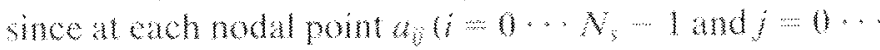

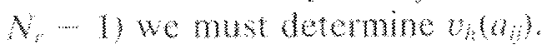

whe linear system is solved by a CG monod. Ths

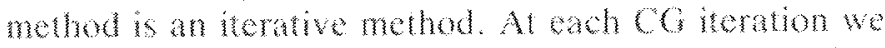

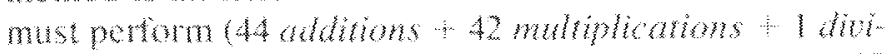
when $\times 4 \times N \times N$, for the contorming $F \mathrm{EM}$ and 18

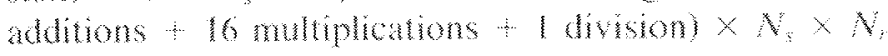
Grths $\mathrm{CMN}$. 
Consequenty, if we ensider the same number at

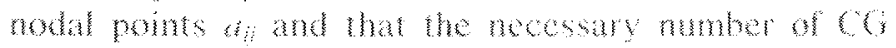

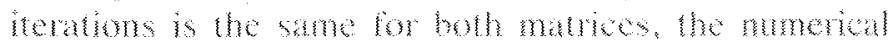

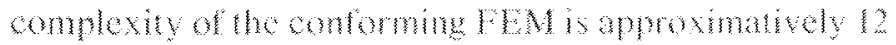

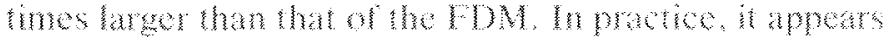

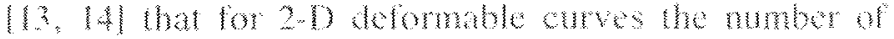

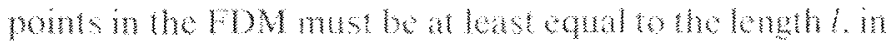
pixels, of the mind guess, to cmpute acumely the

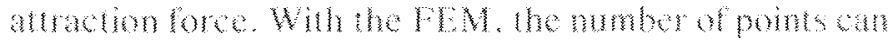

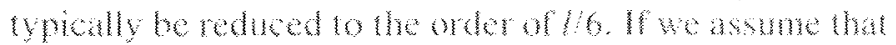

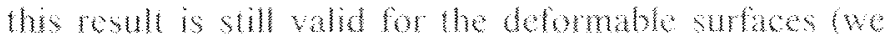
have not implenened the FM tor domable su-

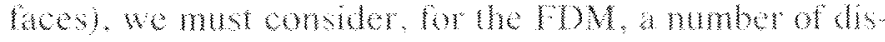

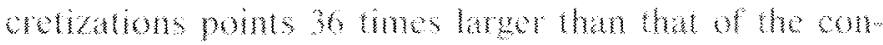

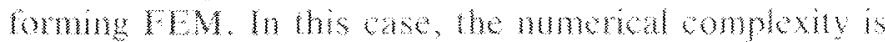

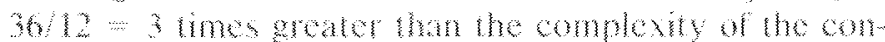
Coming: IPN

The alumage is the to the conputation of the acto $L_{3}:$ in $(13)$ and the nature of the metwot. In the dasteat

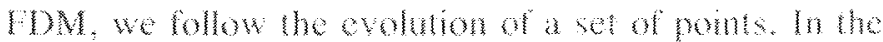

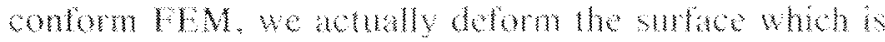
betwen the points of the grid and the mage forces be

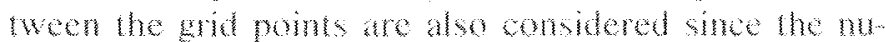

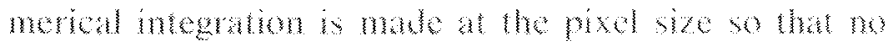
momation is los (seesection 5 , a).
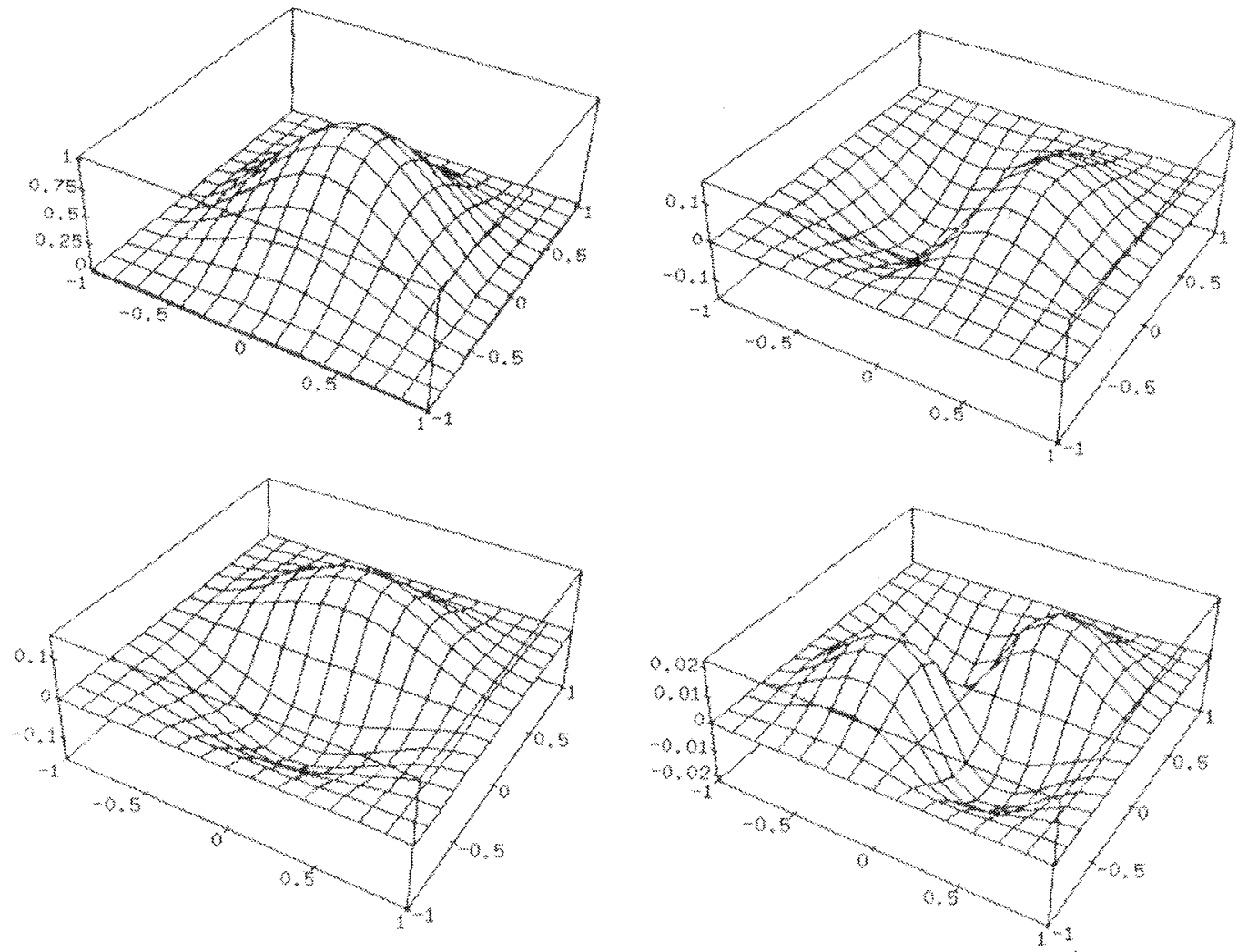

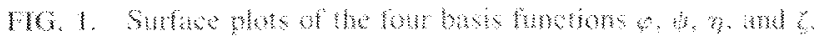

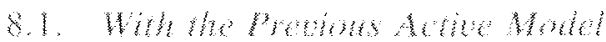
of the surtace us,

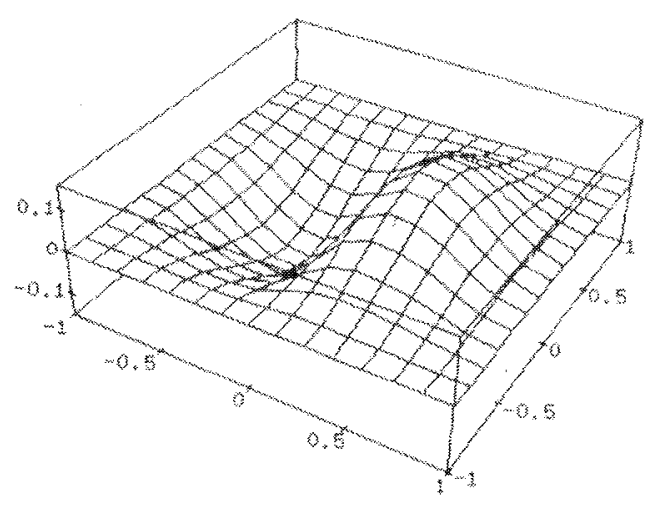

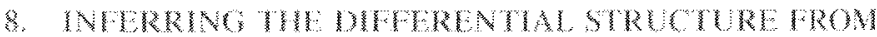 BD M MCES}

In the prows serons we showed how to whe the

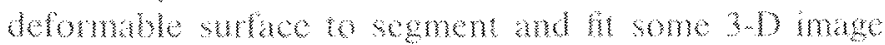

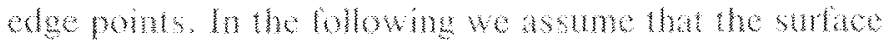

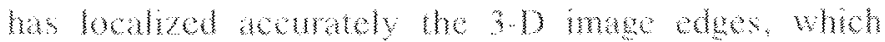

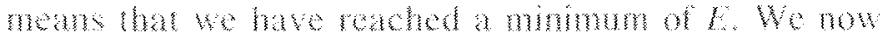

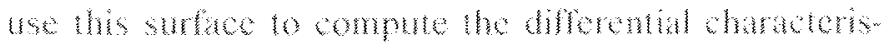
lies of the 3 D inage surbe bonday. The computation

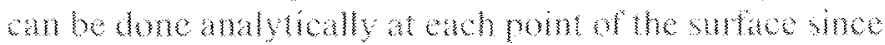

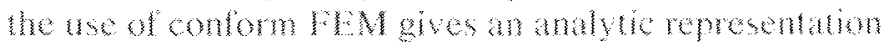

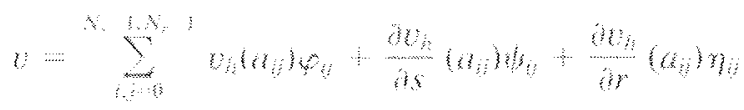

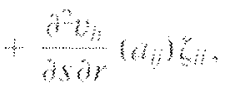

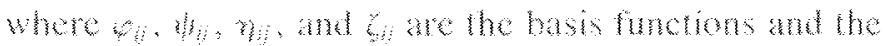

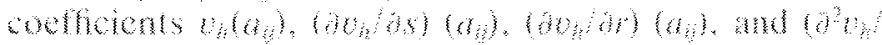

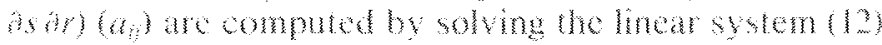

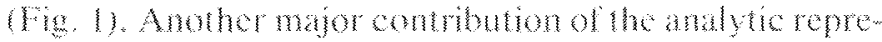


sentation is that at ench point of the surface, the whent

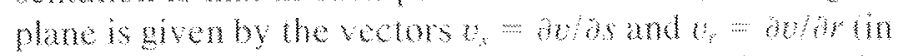

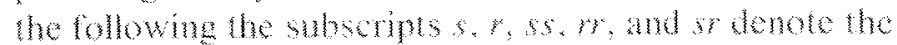
fust and second doriativest. This alows us to compute all the drerentid chameristes in lock coordmates and conseguenty mathe nowe general simatims.

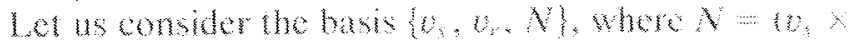

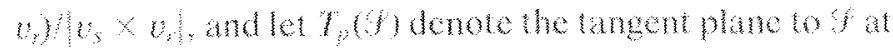

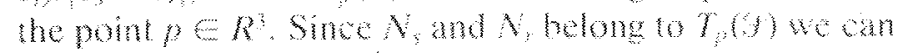
witic

$$
\begin{aligned}
& N_{x}=a_{n} b+a_{n} \\
& N=40+40 \% \text {, }
\end{aligned}
$$

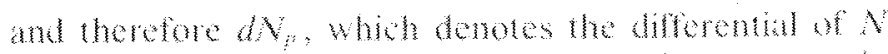

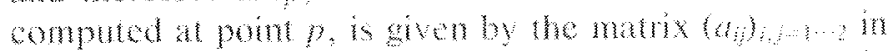

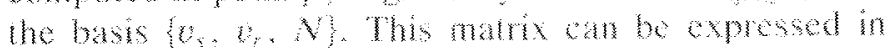

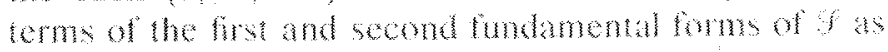
(1)

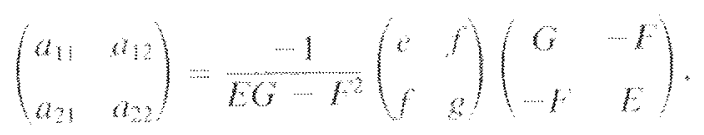

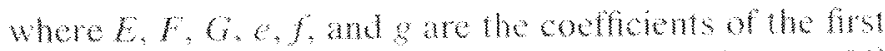

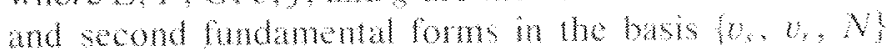
dethed by

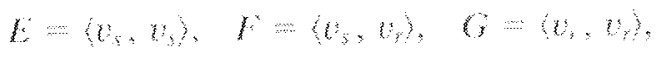

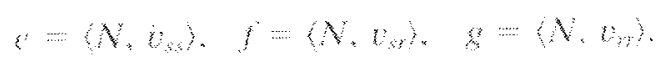

The gives the relatoms

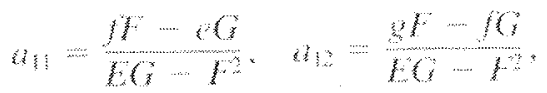

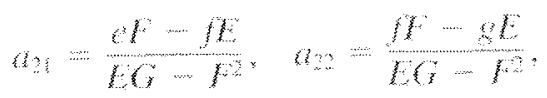

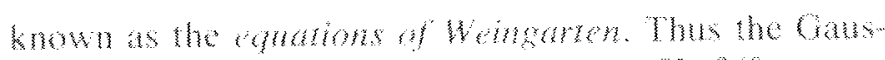

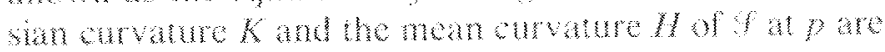

$$
\begin{aligned}
& K=\operatorname{den}\left(\mathrm{k}_{m}\right)-\operatorname{der}\left(z_{3}\right)=\frac{8 g-J^{2}}{\operatorname{Eg} \cdots}
\end{aligned}
$$

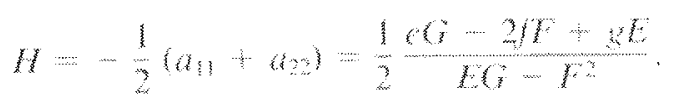

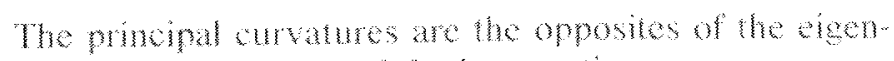

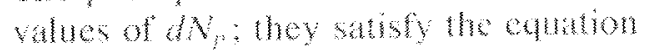

$$
\begin{aligned}
& \text { deth } N_{2}+k=k-2 M k+k=0 \\
& \text { and herefre } k=H+\sqrt{k-K} .
\end{aligned}
$$

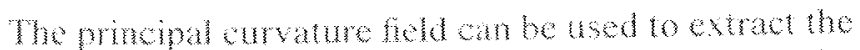

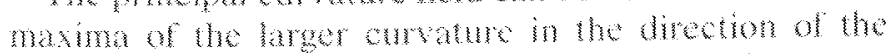

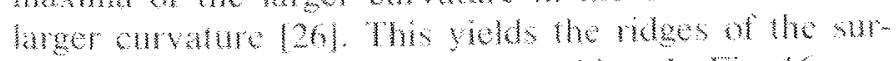

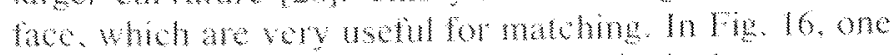

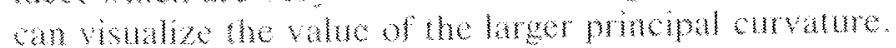

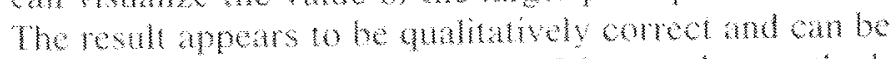
compreat to those obmind in $26 /$ by another nethed.

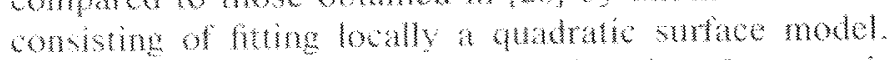

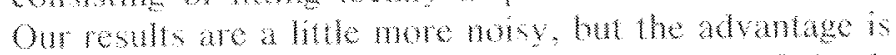
Wat the segmontation and curature are computed simul

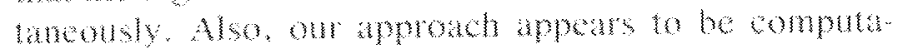
timaly much less apensive.

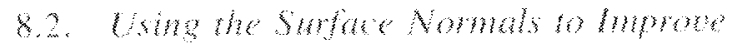 Hate Mathel}

In the previsus examplo the computation of the curva

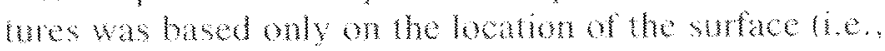

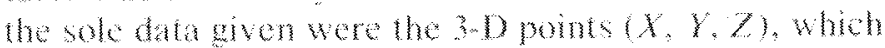

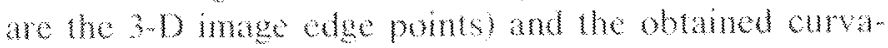
mes are qualiandy comect. but the curvature does not vary smothly. We holeve that the use of adhional inbmation such as the nomals of the surace improves the cesul of the computation of the survares. Monga

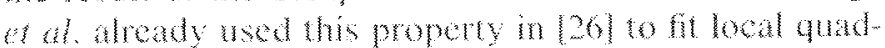
nos models to 3-D abels. Lee [3y used positons and momals to wh sutaes fusm binocular stereo and photo-

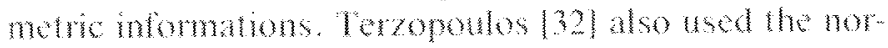
mal information for sumes himb.

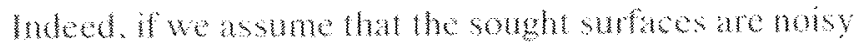

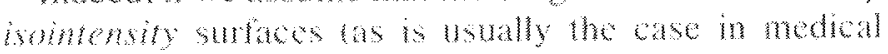

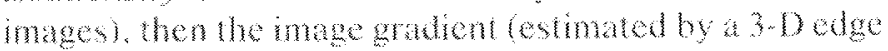

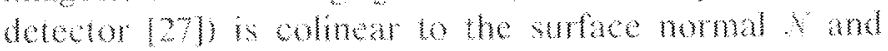
povies un incomation.

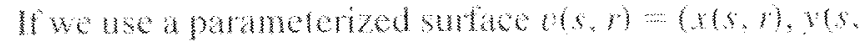

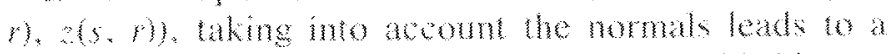

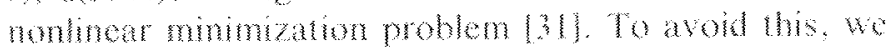
use a propery of regula sumes which sates that for

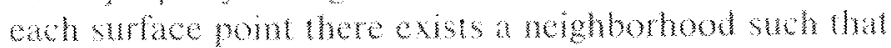

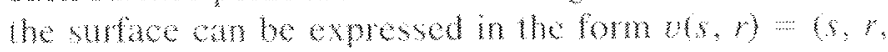

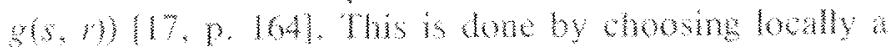
reference bume sum that he frot wo vectors ot the basis bolng to the rangen plane. We call his referme

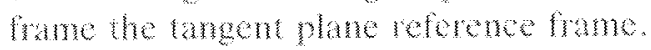

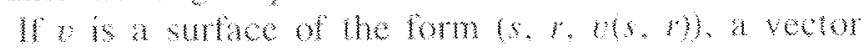

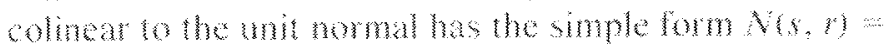

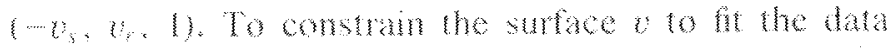

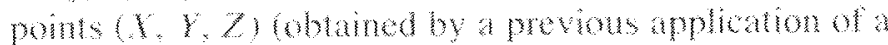
simple dofmable molet) and the nomals (estmated

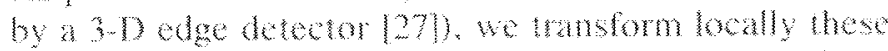

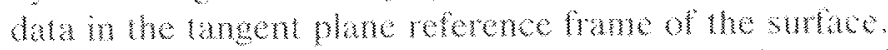

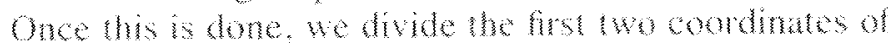

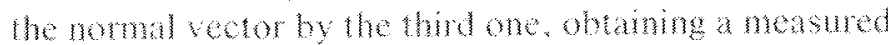

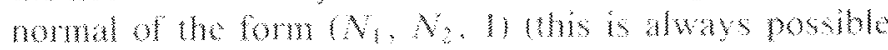




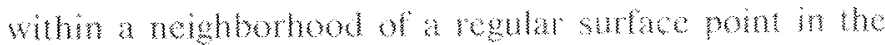
tangen plane refence tranes.

We an now lefine a hew energy given by $k=$

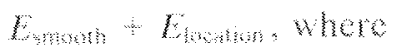

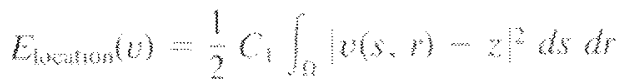

$$
\begin{aligned}
& +\frac{1}{2} C, \int v_{n}(x, r) N d n \\
& \left.-\int(U, r, n)-N^{2} d s d r\right)
\end{aligned}
$$

where represent the thro compunent of the probeton of the data poun $(X, Y, Z$ ) in the tangent plate retorence fanc.

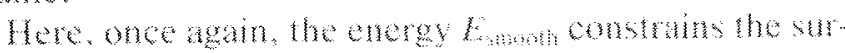

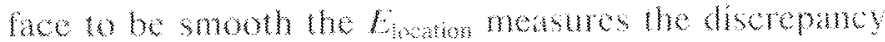
between the dat and the surace, the coethonens $C$ and

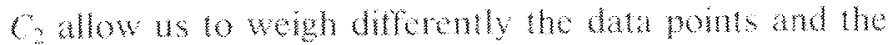
nomals. This allows us to choose the conterents $C_{\text {ind }}$ $C$ depending on the rabiny of the data poins of the nomals (up to now we set $C=C_{2}=1$ ).

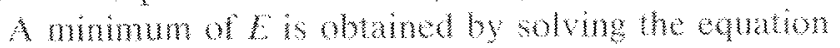

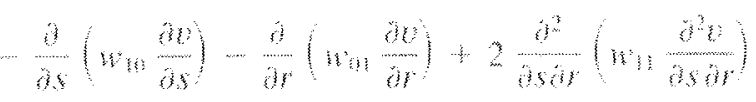

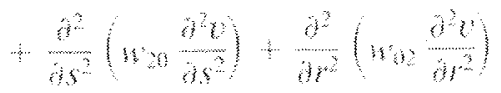

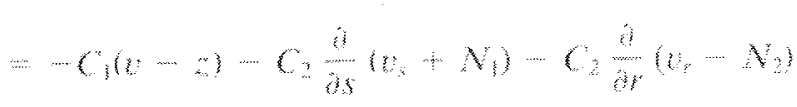

\section{boundary conditions.}

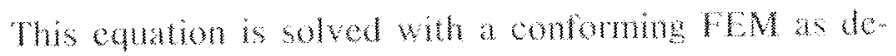
scribed in secton 5.

\section{EXEREMENTAL RESULTS}

We now give resuls of the dignthms mesented so tar.

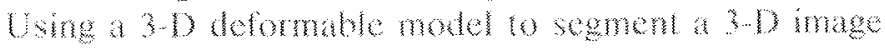

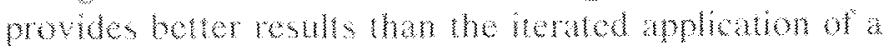
2. deformable model to successve 2-1 cross sections

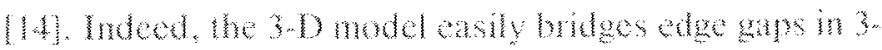
D. i.e. not ony whm a coss secton hut alsoburen cross sections, cowming that the resul solobaly a smow sutace and not ony a colledion of smoth pha

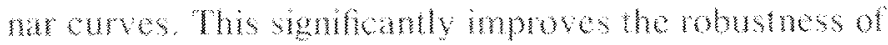

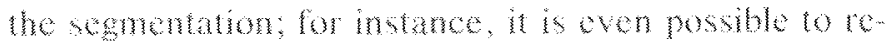

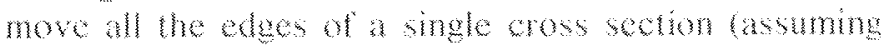

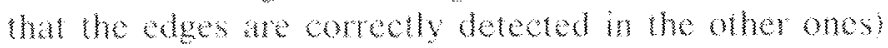

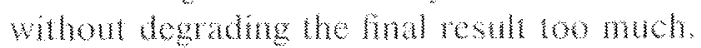

We preson tin ris. 2 an example wh arthid data. This higue represents overtas of some horizonal cross soctoms of the mind surae whe the mignal dat The 3 D image here is a cylinder where have removed come edyes in the stowstre cross sefions bompare

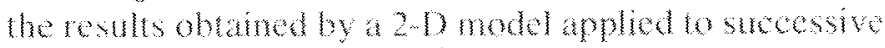
cross setions whl hose of an $3 \mathrm{~m}$ deromable model.

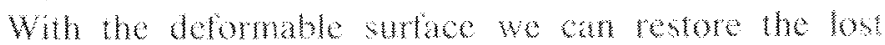
soges and oban anter reconstruction of the cyluer

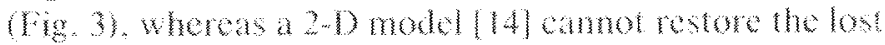

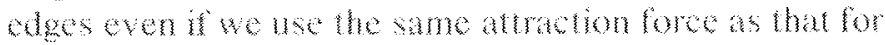
the 3 - $D$ moucl.

The beromate model can also hande nosy dati. In

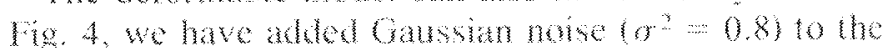

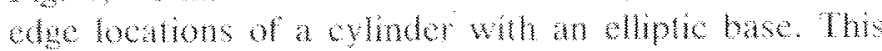
ligme shows some cross sectons of the obtumed surface wh the bata and a represtution of the surbee. We have also conducted some ceperments on the acerac of the model and its ablut forde hosy data. Wa hase considered a sel of dixa pone carface plot is given in

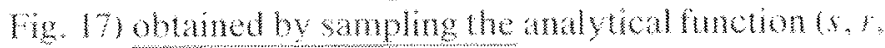

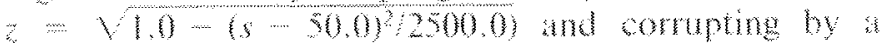
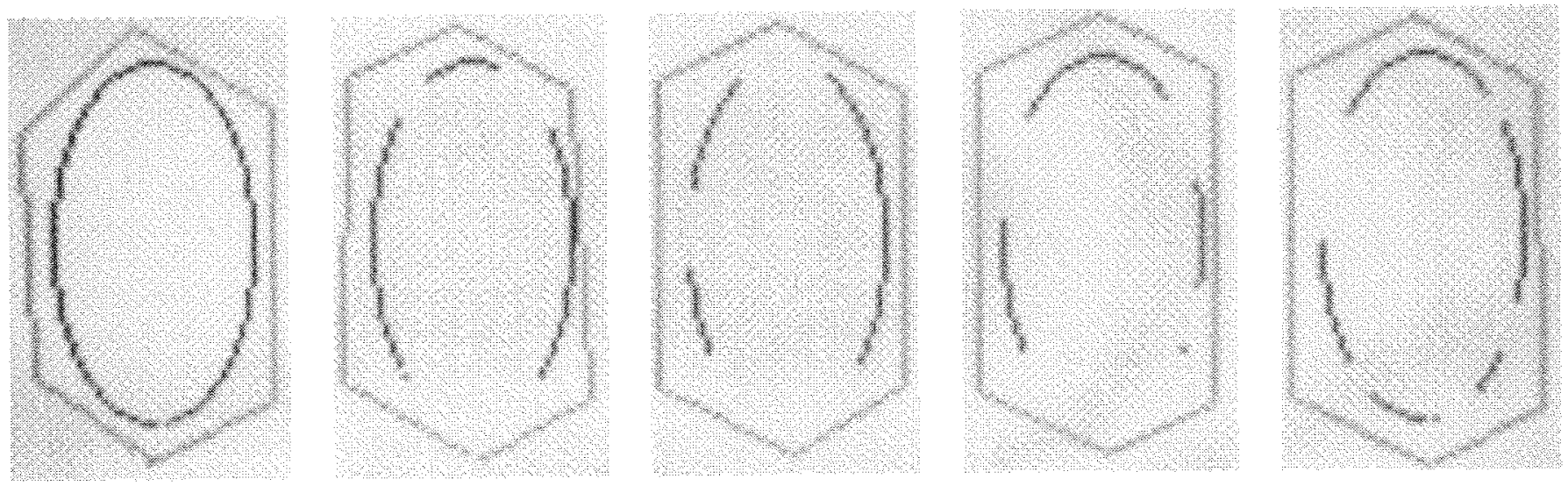

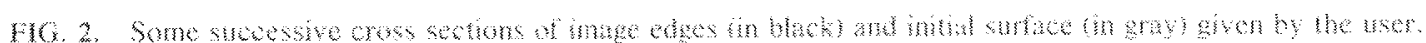



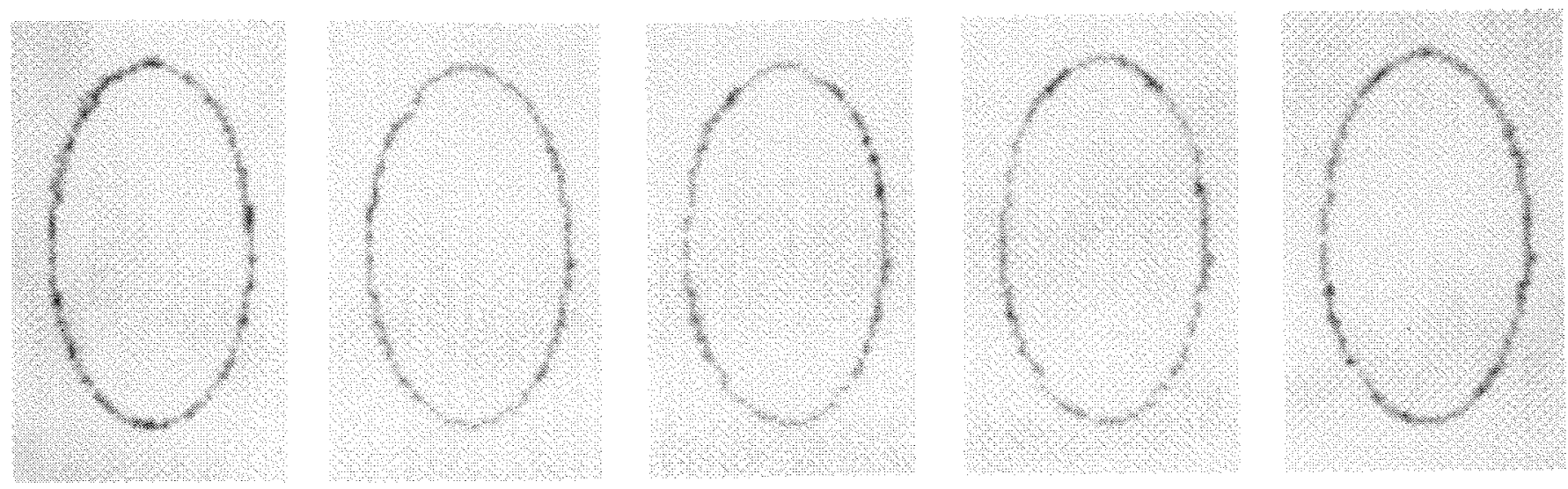

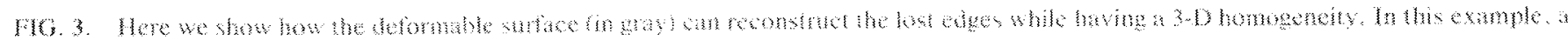

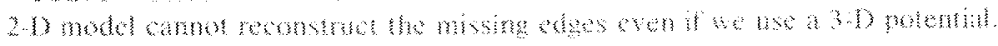

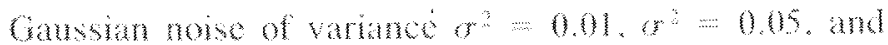

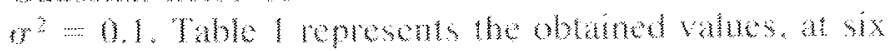
Wheren points, of the sumace appoximatio the func-

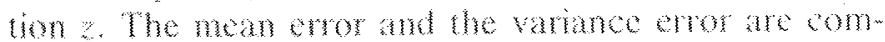

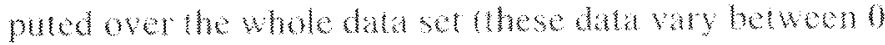
and 1

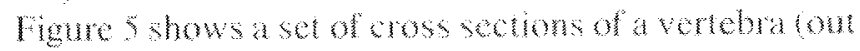
of a total of 50 cross sectoms botaned wh an $x$-ray scamer and the intal segmenaton proved by the wsy the external cures shw the inersection of the gach surace whth the corresponding crass sectims

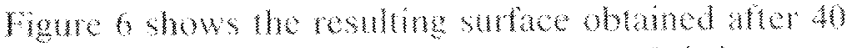

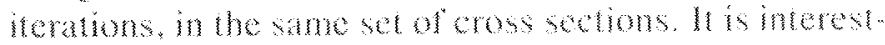

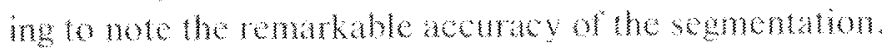

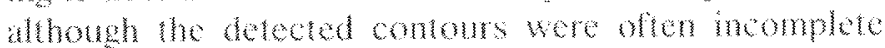

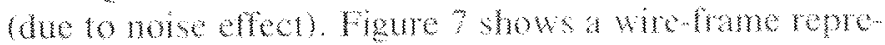

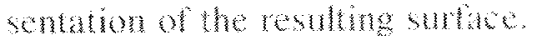

Figure s ropresents some cross sections of the 3 )

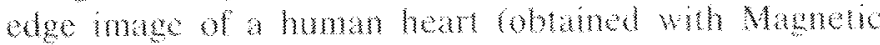

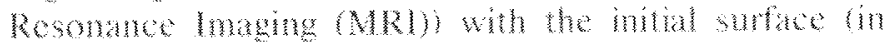

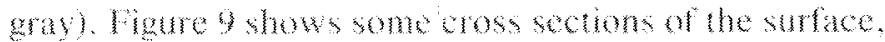
onee it has rached the mimmm of $E$. We can note the

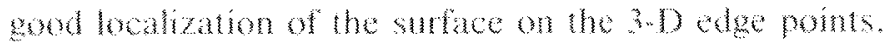

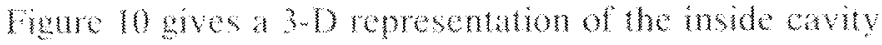
athe kit ventrict

ligue I represens some cross sections of a hmmat hext tout of 70) obthed whin MRL. Mgure 12 shows some ross setions of the sulace with the 2 D inages. A

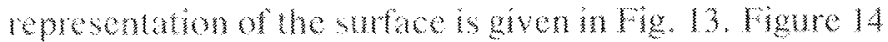
shows the coss sectons of the surlace obtand on an oher ser of WR images and wig. Is a rendered represen ation of the suthes.

We mon presen the restls of the compunation of cur

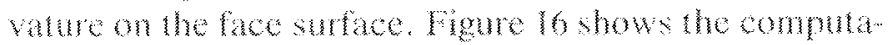
ton of the laver value of the wo principal curvatures.

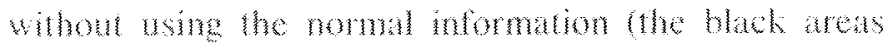
corespond o himeurature regons and fhe high gray areas io lowewvature regions. We can exily remark hat the black areas tend wo chacterize the structures of

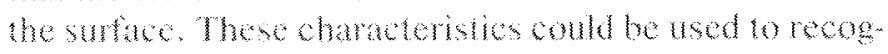
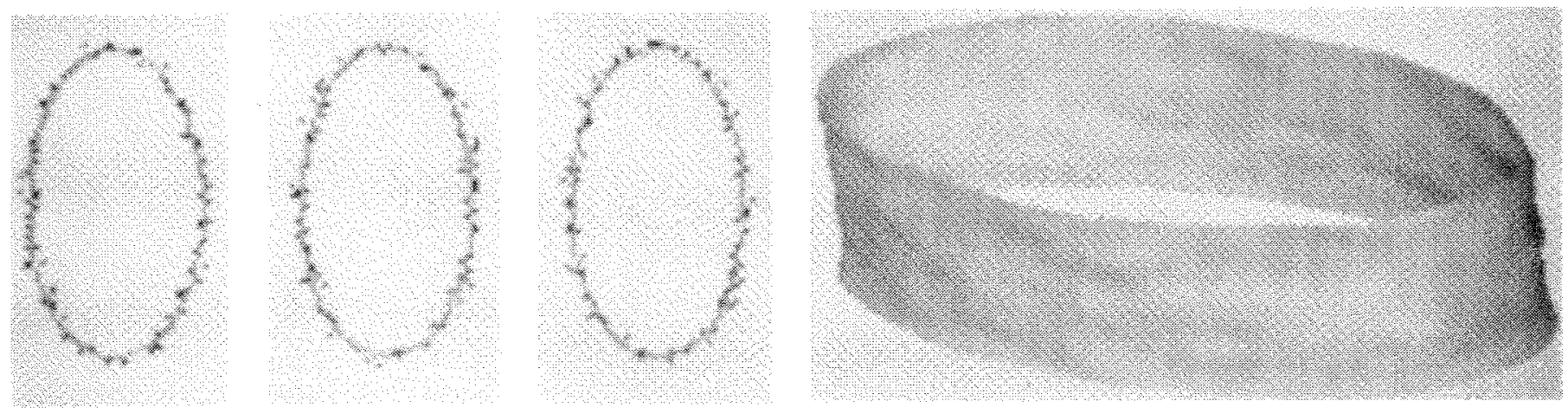

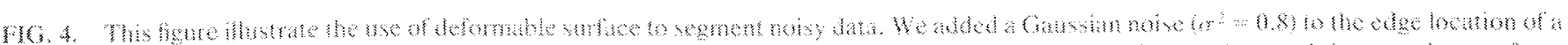

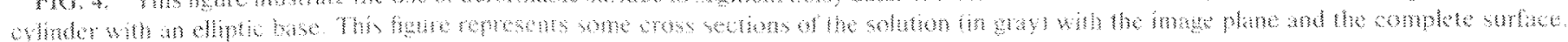



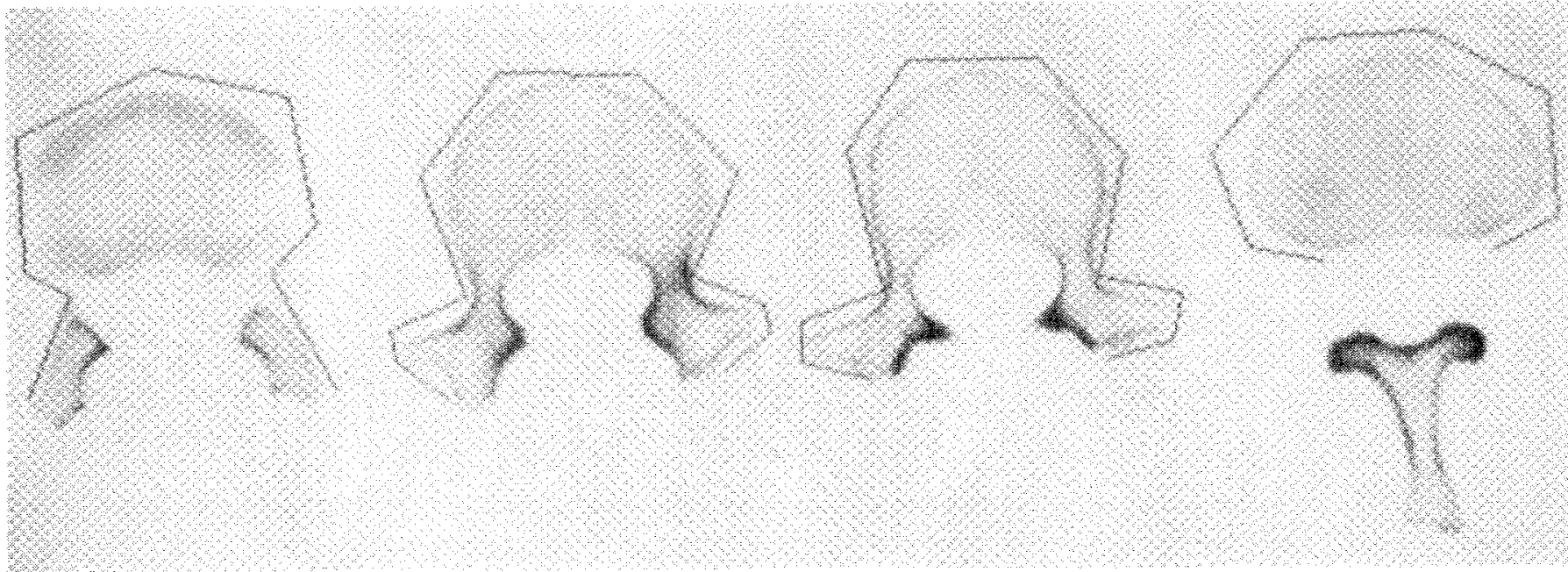

Fo. 5. Sone cons sections of the intidat sutace given by the user
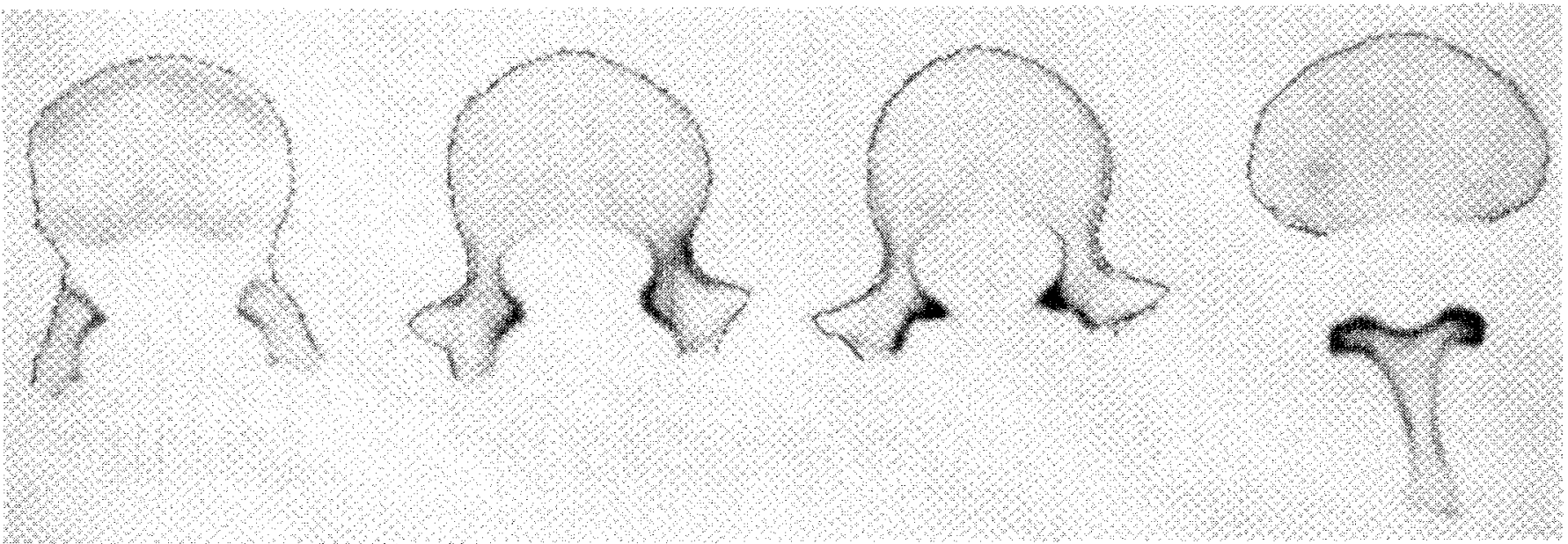

FIC. 6. The corroponding cross sections of the solution.

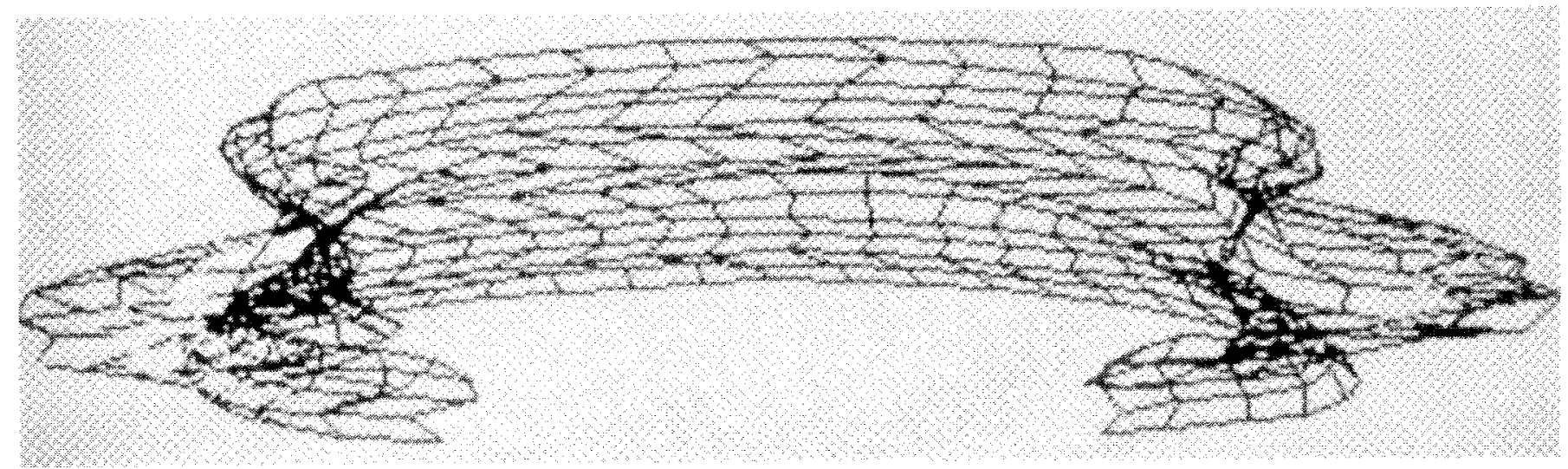

Fo. 7. A wire frme representaton of the rerebra. 

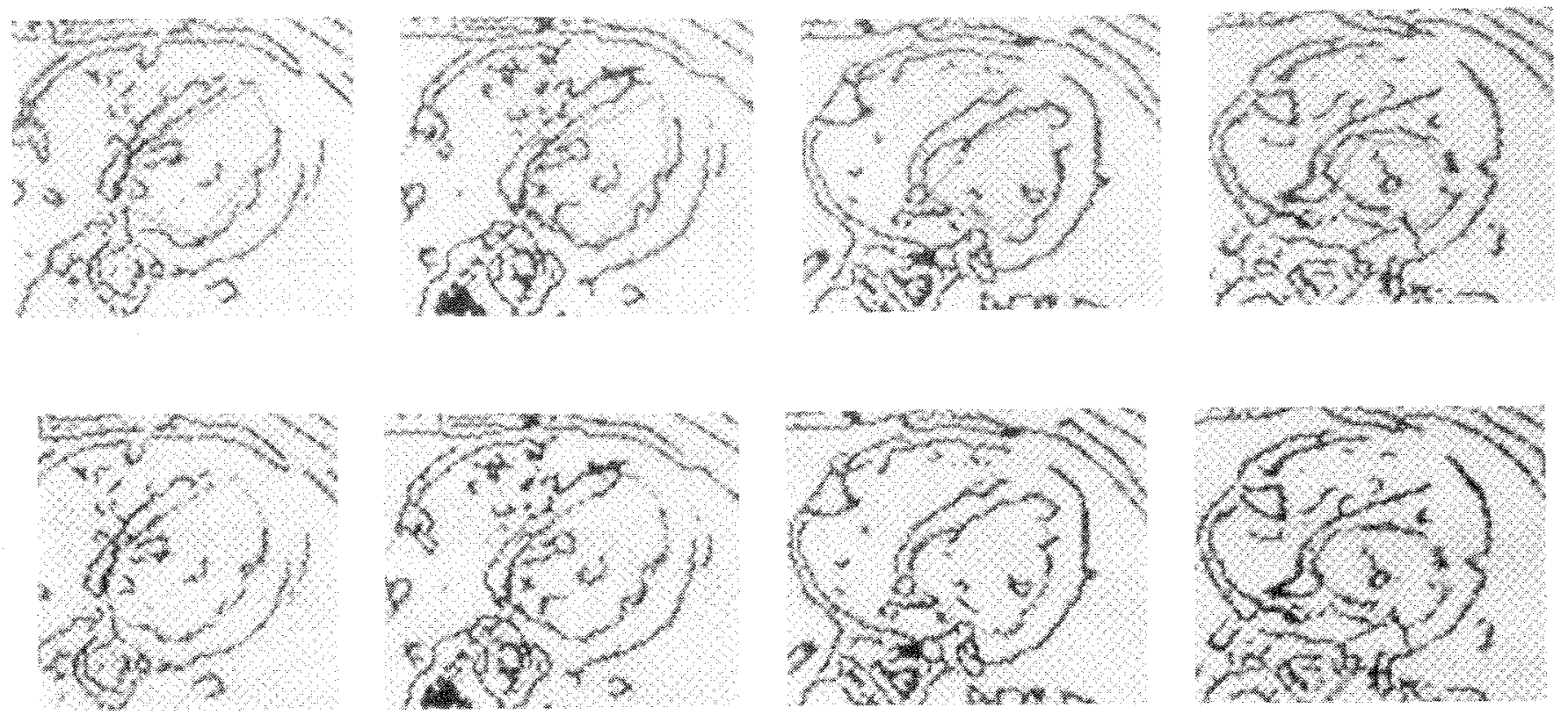

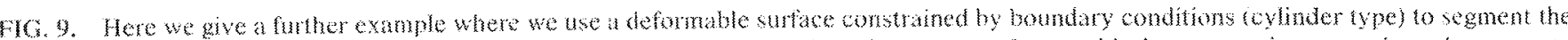

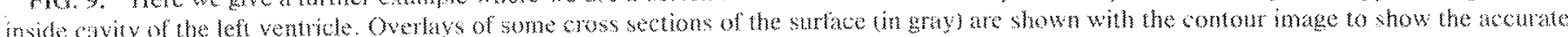
wonlization of the surface

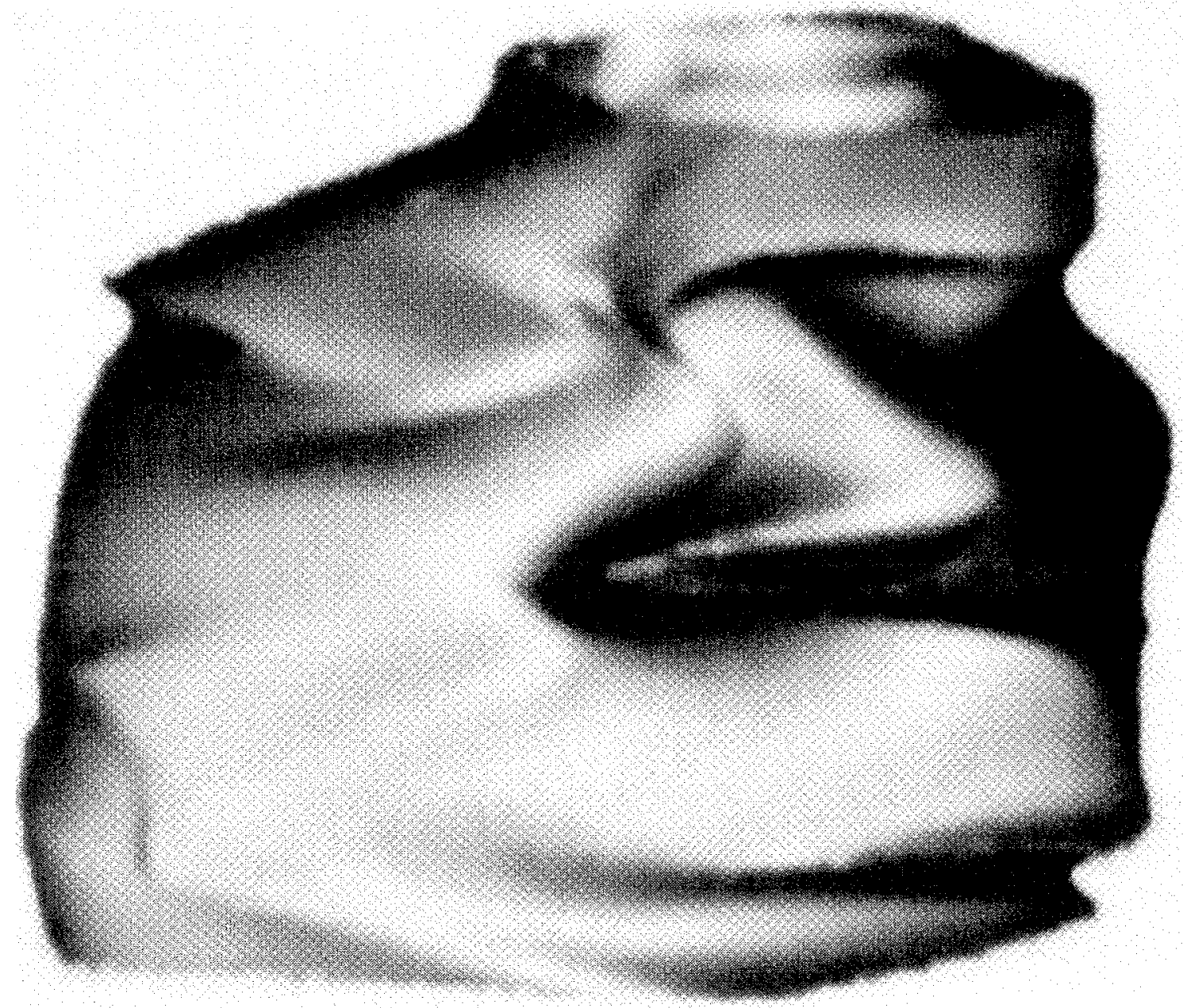

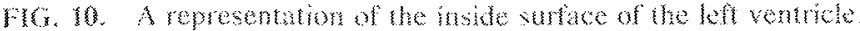


TABLE 1

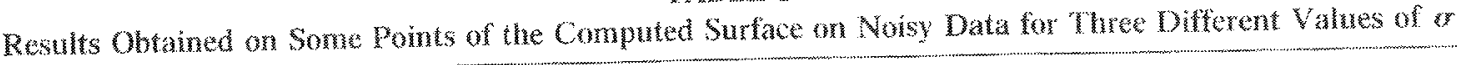

\begin{tabular}{|c|c|c|c|c|c|c|c|}
\hline \multirow[b]{2}{*}{ Poines } & \multirow[b]{2}{*}{$\begin{array}{c}\text { Theoretical } \\
\text { value } \\
2 . t\end{array}$} & \multicolumn{2}{|c|}{$\gamma^{2}=0,01$} & \multicolumn{2}{|c|}{$x^{2}=0.65$} & \multicolumn{2}{|c|}{$y^{2}=1.1$} \\
\hline & & $\begin{array}{c}\text { Compued } \\
\text { value } \\
z_{5}\end{array}$ & 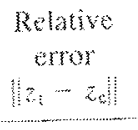 & $\begin{array}{c}\text { Computsed } \\
\text { value } \\
\varepsilon\end{array}$ & 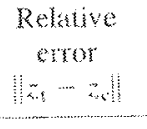 & $\begin{array}{c}\text { Compuned } \\
\text { vahe } \\
z\end{array}$ & $\begin{array}{l}\text { Kelaupe } \\
\text { arou } \\
6\end{array}$ \\
\hline$(0,375,0,5)$ & 0.9682 & $0.8 \times 70$ & 0.0812 & 0.8609 & 0.1073 & 0.8333 & 0.1349 \\
\hline$(0,5,0.5)$ & 1.0000 & 09183 & $0,081 \%$ & $0,89 \% 3$ & 0.1027 & 0.8513 & $0.148 ?$ \\
\hline $0,75,0.5)$ & 0.8660 & 0.8090 & $0.05 \%$ & 0.7600 & 0.6970 & 0.6805 & 0.1855 \\
\hline$(0.75 .0 .5)$ & 0.9682 & 0.3796 & 0.6886 & 0.8302 & 0.1380 & 0.7803 & 0.1879 \\
\hline$(0.5,0.25)$ & 1.0600 & $0.90 \%$ & 0.0923 & 0.845 & 0.1555 & 4.7598 & 0.2402 \\
\hline $0.75,0.75)$ & 0.8663 & 0.8243 & 0.0417 & 0.8313 & 0.0347 & 0.7981 & 0.069 \\
\hline $\begin{array}{l}\text { Mean errot } \\
\text { Variance error }\end{array}$ & & \multicolumn{2}{|c|}{$\begin{array}{l}0,0658 \\
0.0175\end{array}$} & \multicolumn{2}{|c|}{$\begin{array}{l}0.0878 \\
0.0316\end{array}$} & \multicolumn{2}{|c|}{$\begin{array}{l}0.1609 \\
0.0800\end{array}$} \\
\hline
\end{tabular}

nize anatomical structures from the $3 \times \mathrm{D}$ images. Never. theless, as discussed betore, the results are qualitatively comect, but noisy.

To validate the use of the nomal, we conducted a series of experiments on synthetic data. II Fig. 17 a rendered representation of the data and the theorefical value. of the larger value of the two principal curvatues are shown. We have added Gaussian noise $\left(\sigma^{2}=0.01\right)$ to
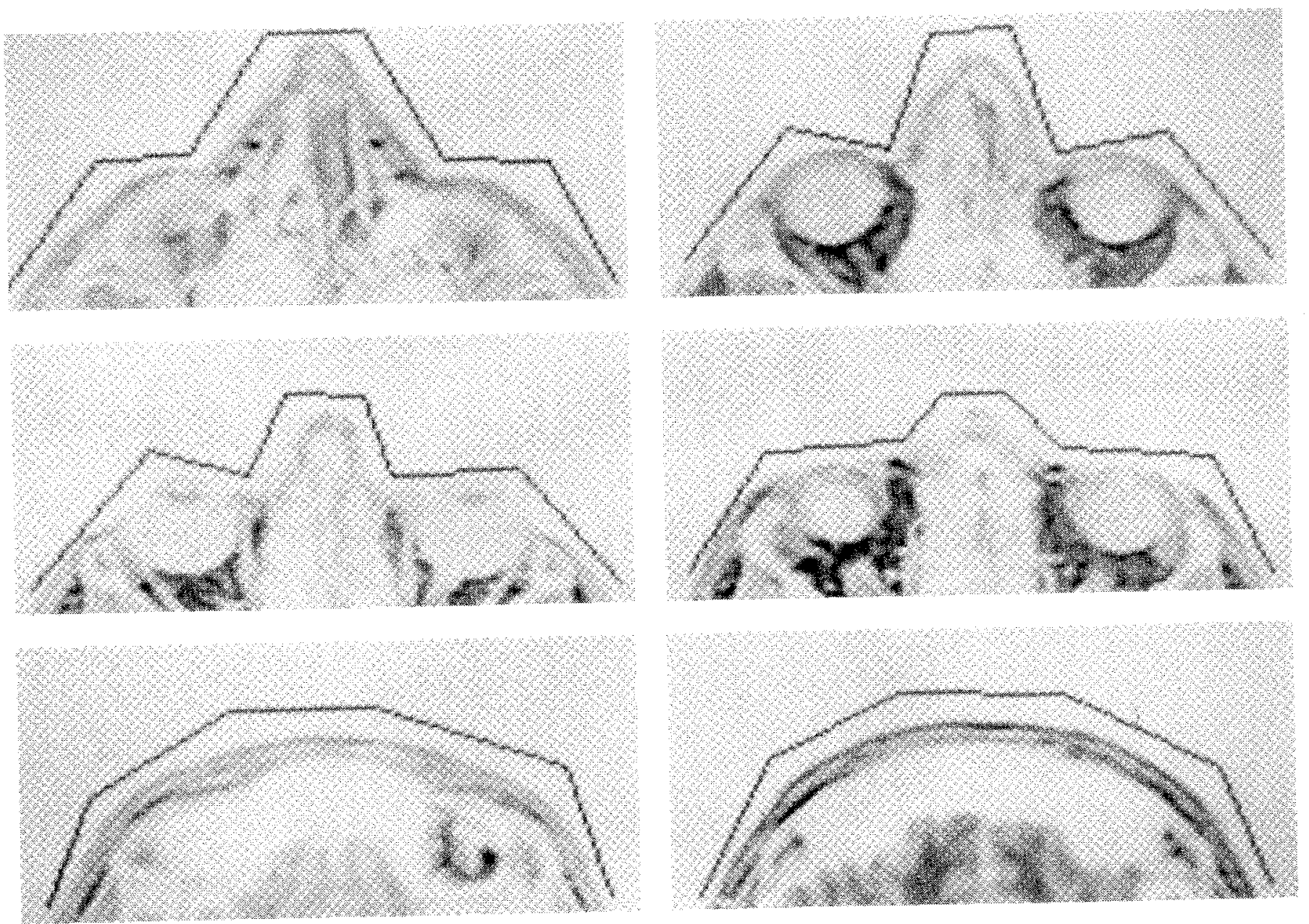

Fa. 11. Oxentays of some cross sertions of the initial sufface given by the aser with the origual data. 

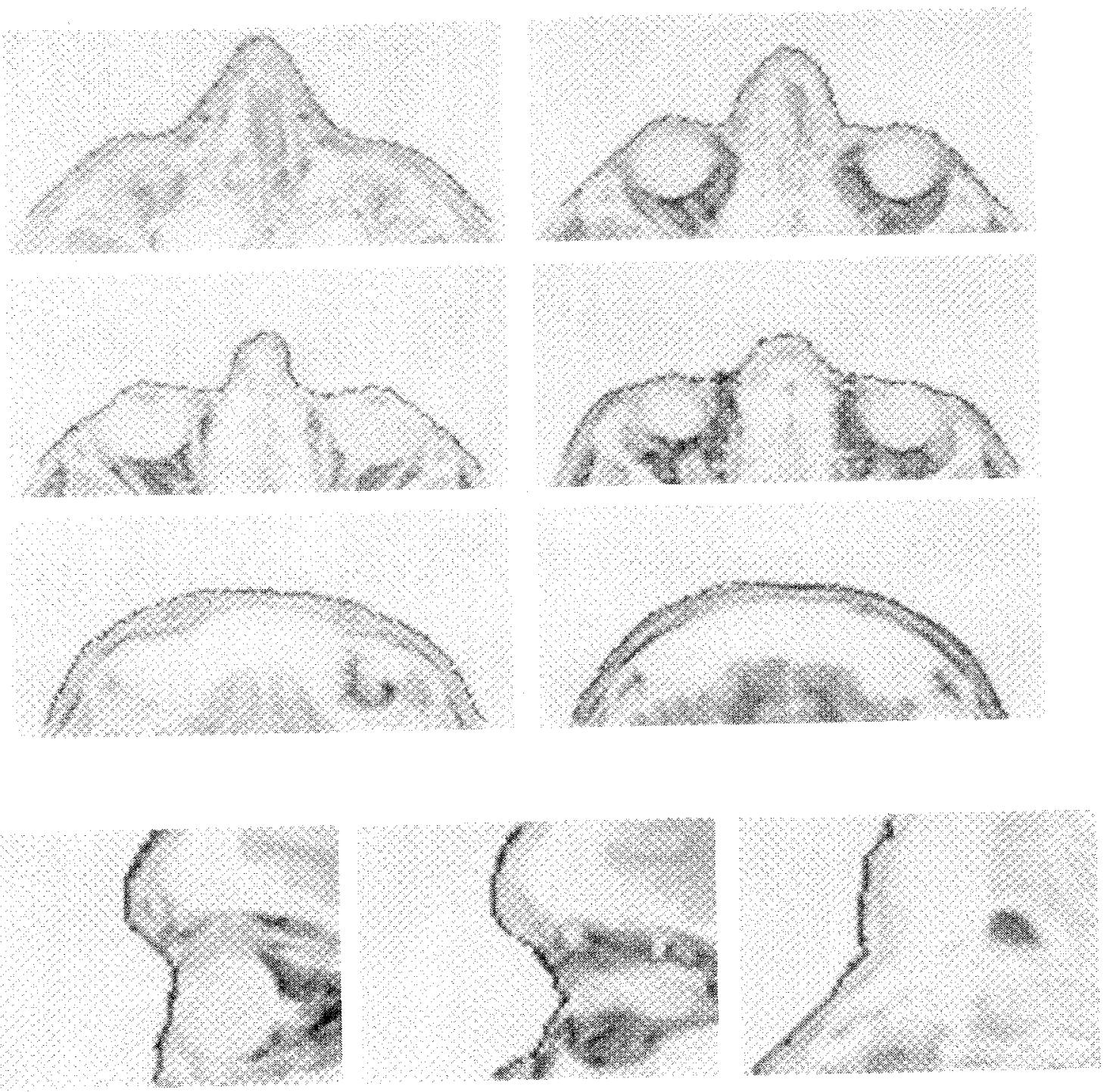

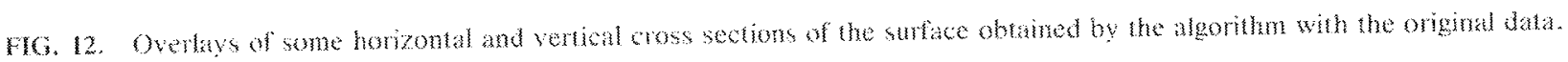

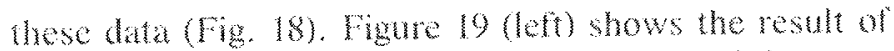
approximating the surface to the notsy datand the conputation of the curvare information (Fig. 19 . right) whout the use of the normals. Figure 20 (1ight) shows the same quantitis computed with the information of the surtace nomals and demonstras the importance of this intormaton for regutrizing the result. This risual qualintive improvement is confmed by a qualitive compar ison of the conputed secondmoter derivaties at ditercon ponts on the surace. Typiedly, a gan of loy in the accuracy of the second onder derivives is provided by the nomal inomation. Table 2 show the larger value of the principal cuvatures at the distinct poins.

\section{CONCUSTON AND WUTURE RTSEARCH}

We have shown how a doformable surface can be used 10 segment 3-D images by miminzing an approprate energy. The minmization process is done by a vational method with a contorming finite element. On method, inchung the use of an adaptive subdivion for fore computation has the following alvantages:

1. it recuires less discretization points and conseguenty produces a smaller linear system to be solved, thus reducing signifanty the algorithme complexity. and 


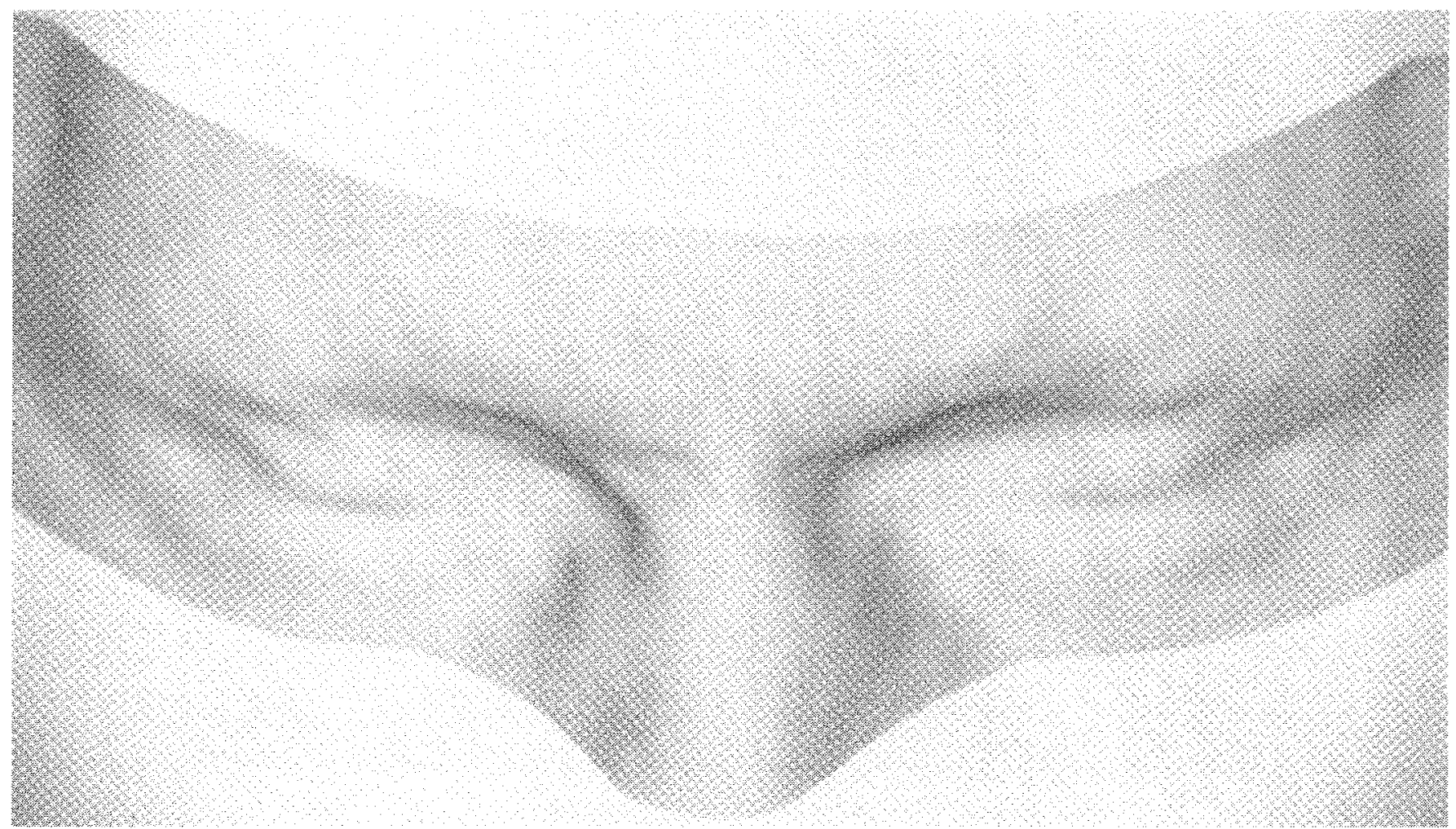

Fic. 13. A 3-D reperentation whe surace.

2. it provides an analytical representation of the surface.

This last feature is the most important one for inferring differental structures of the suface, and we showed how to compute the first and second fundamental forms of the defomable model. These charateristics provde a help. ful tool for recognizing $3 \mathrm{~N}$ objects. They will be used soon to match the deformable suface to an anawoncal atas $[2]$.

\section{APYWNDTX $A$ : SURFACE AND 3.D EDCE POWNS}

In this frst appendix we give a necswry and suffeient condition for a surface to produce a local extremum of the wergy

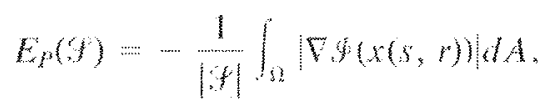

where $|S|=\iint_{n}\left|x_{5} \times x_{n}\right| d x d s$ and $d x=V E G-F^{2} d x d r$ is the standard surace area mesure. A necessay and sufferent condition for the sutace $f$ to produce a lowal cxtremum of $E_{p}$, with respect to infintesimal deforma tions is

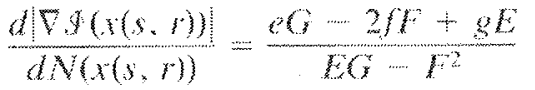

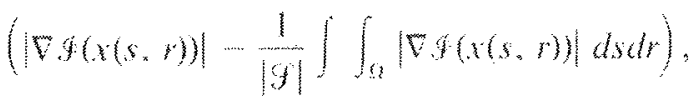

TABLL 2

The Comparison betwen the Larger Value of the mincipal Curvature Computed on Noisy Data with and

\begin{tabular}{|c|c|c|c|c|c|c|}
\hline \multirow[b]{2}{*}{ Poinis } & \multirow[b]{2}{*}{ Theortical $k$} & \multirow{2}{*}{$\begin{array}{l}\text { Perfect data } \\
\text { Computed } \\
\text { cumame }\end{array}$} & \multicolumn{4}{|c|}{ Norsy data } \\
\hline & & & $\begin{array}{l}\text { Wibinoul } \\
\text { nommal }\end{array}$ & $\| k_{:} \quad \cdots \quad k$ & $\begin{array}{l}\text { With } \\
\text { nommats }\end{array}$ & $\left\lfloor k_{z}-k_{n} \mid\right.$ \\
\hline$(0,25,0.5)$ & 2.658 & 2.118 & 1.846 & 0.812 & $1.9 \%$ & 0,734 \\
\hline$(0.5,0,75)$ & 1.609 & 1.687 & $162 \%$ & 0.018 & 1.605 & 0.004 \\
\hline$(0.65,0.5)$ & 2.141 & 1.576 & 1.748 & 0.409 & $1.80^{3}$ & 0.340 \\
\hline
\end{tabular}
whout the Use of Normals 

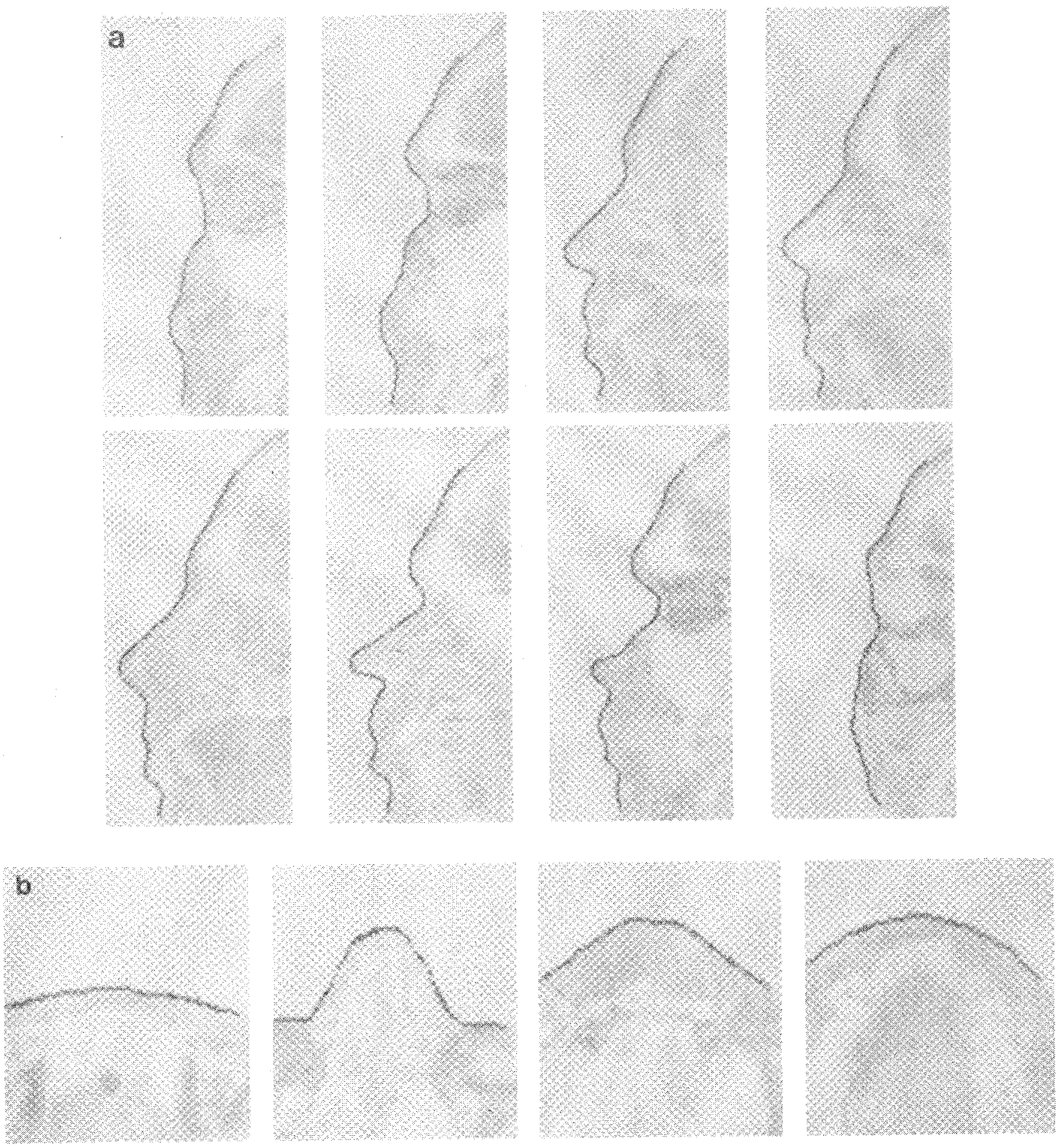

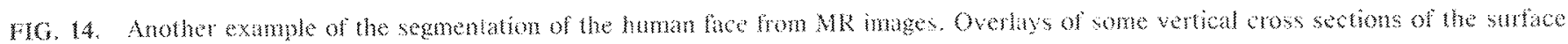
obianed by the algwihm wh the onginal data.

where $E(s, r), F(s, r), G(s, r), \ell(s, r), f(s, r)$, and $g(s, r)$ are the coefterents of the hirst and second fundmeval fom in the basis $\left(x_{5}, x, N\right.$ ) (see $[7]$ for detals about the notalions), $\Omega=[0, L] \times[0, M]$, and $l=[\nabla$,
Let us consider $y$, a small defomation of the surface $y$ such that the paramerizaton of $y$ is

$$
x^{2}=x+\lambda\left(\alpha x_{s}+\beta x_{z}+y x\right)
$$




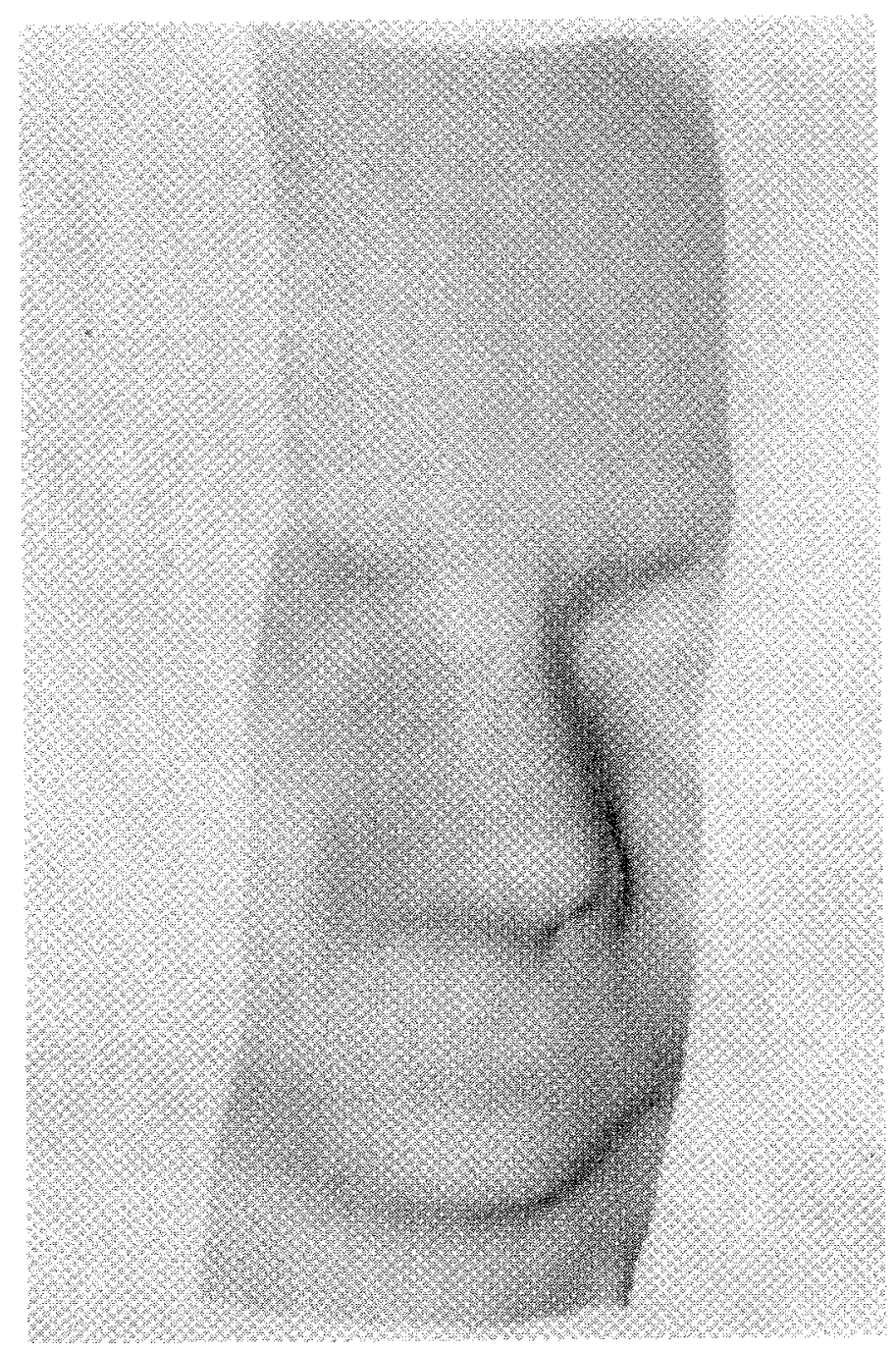

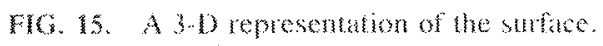

where $\alpha(\%, r), \beta(s, r)$, and $y(n, r)$ are abitrary contimous and differentable functions and $x, x$, and $N$ are the derivatives of $x$ and the nomal to the surtace.

$y$ is a lowal extremum of $E_{z}$, if and only if

$$
\left.\frac{d E_{s}\left(C_{\lambda}\right)}{d \lambda}\right|_{x \rightarrow 0}=0
$$

for all $\alpha, \beta$. and $\gamma$.

We show that (19) holds if and only if (17) is satisfed. By dehnition

$$
\begin{aligned}
& E_{p}\left(Q_{n}\right)=-\frac{\int\left(P^{2}\left(s_{n} r\right) d A\right.}{\int_{1} d A}
\end{aligned}
$$

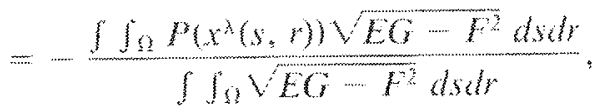

where $F, F$ and $b$ are the coefleculs of the furst funda mental form of $y_{x}$.

To compute the derianve $\left(d E_{1}\left(Q_{A}\right) / d k\right)$ hen. we ned to compute the lerivaves of the vectors $x_{n}, x$, and $N$. For the purpose we use the equatons $117, \operatorname{sect} 4.3$. p. 2311

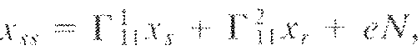

$$
\begin{aligned}
& x_{r}=x_{m}=M_{2} x_{3}+T_{2} x_{r}+h_{0} \\
& x_{y}=\Gamma_{2} x_{2}+\Gamma_{2}+8 N
\end{aligned}
$$

where the combients are the Chrototel symbols of in the parametration $x$ and $e, y$ are the codfotens the second turdamental tom of 5 . In the following the Chistofel symbols I have been replaced in terms of the coeffichts of the frot fumbmental form $E, F, G$ and their derivatives.

Thus computing $d E_{p}\left(\delta_{n}\right) / \lambda$ and ovaluating it at $\lambda=0$ lads to

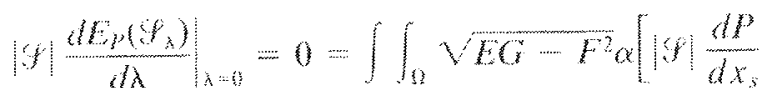

$$
\begin{aligned}
& \left.+\left(9 \mid h_{m}\right)\left(\mathrm{N} \|+\mathrm{T}^{3}\right)\right] d \mathrm{~d} d r
\end{aligned}
$$

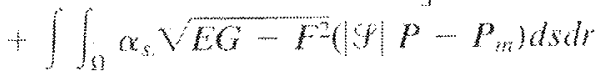

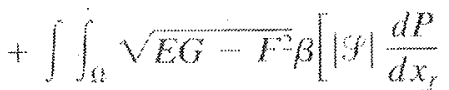

$$
\begin{aligned}
& +\left(H-P_{n}\right)\left(\Gamma^{1}+\Gamma_{2}^{2}\right) \mid d s d \% \\
& +\iint_{0} p_{E G-F}\left(|\varphi| P-P_{n !}\right) d s h \\
& +\iint y \sqrt{E G-F} \mid \frac{d P}{d N} \\
& \left.\left.-(\mid) \mid P-P_{m}\right) \frac{x-2 f F+g E}{\sqrt{E G-F^{2}}}\right] d x
\end{aligned}
$$

where $p_{m}=\int_{0} P d A$.

Integrating by parts the integral (except the last one) yols (17) as a necesary and suffeiont condion for (19) to be satisfed for all $\alpha, \beta$, and $\gamma$.

\section{APPENDIX B: DETALS ON THE NUMERICAL SOLUTION}

\section{B.1. Vuriational Fommataton}

Let $\varphi \in H$ te be a smooth function. If $1 \mathrm{~s}$ is a solution oria. (7), we have 


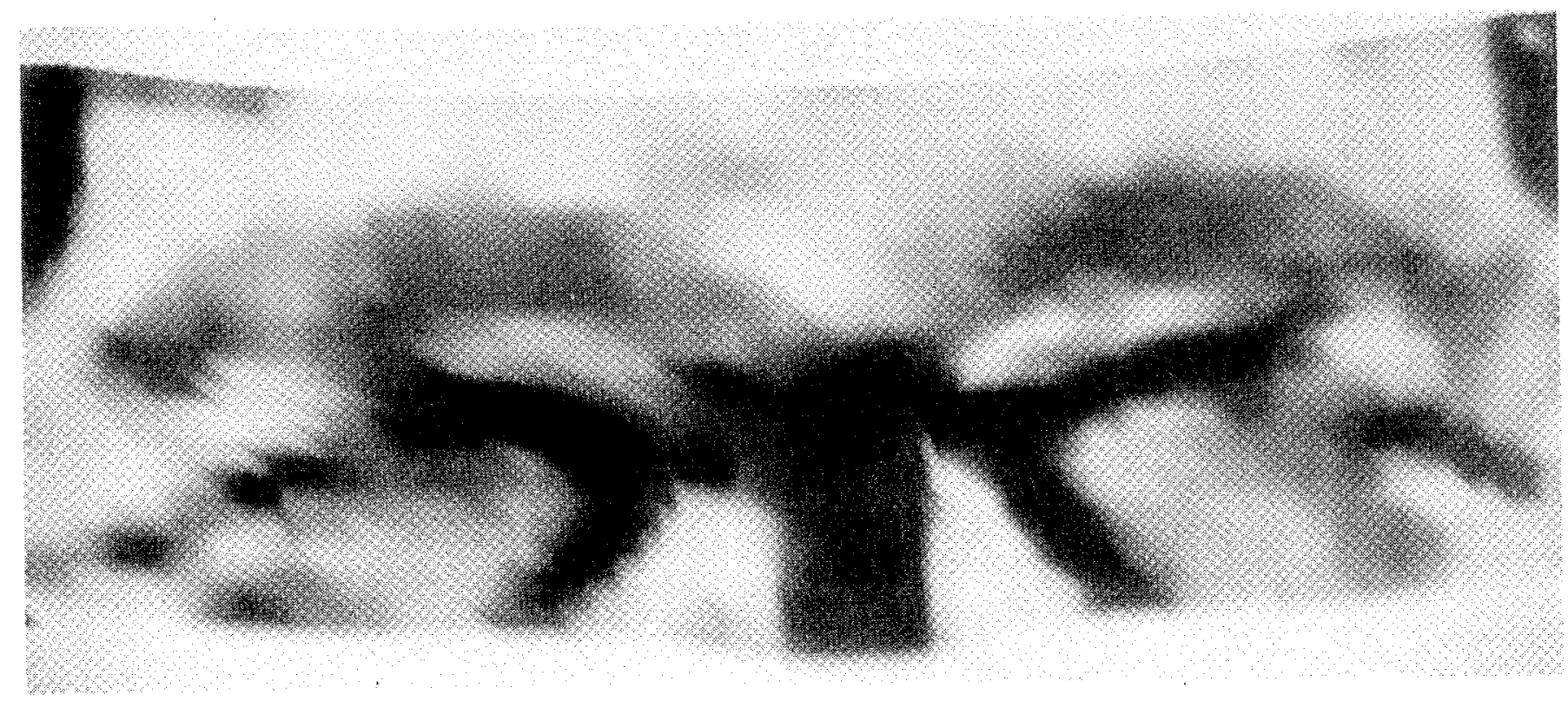

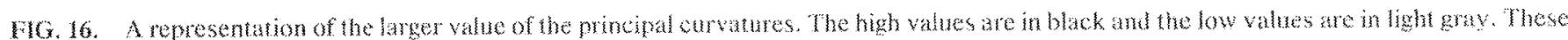

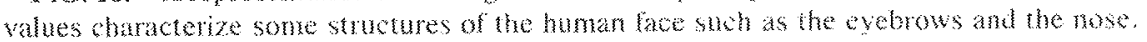

$$
\begin{aligned}
& \int_{n} \frac{\partial y}{\partial t} \varphi d s d r-\int_{0} \frac{\partial}{\partial s}\left(w_{0} \frac{\partial y}{\partial s}\right) \varphi d s d r \\
& -\int_{a} \frac{\partial}{\partial y}\left(w \frac{\partial u}{\partial y}\right) \omega d s d v \\
& +2 \int_{0} \frac{\partial^{2}}{\partial s \partial^{r}}\left(w_{n} \frac{\partial^{2} v}{\partial s \partial y}\right) \psi d s d r \\
& +\int \frac{\partial^{2}}{\partial s^{2}}\left(w_{0} \frac{\partial^{2} y}{\partial s^{2}}\right) \varphi d s d x \\
& +\int_{a} \frac{\partial^{2}}{\partial r^{2}}\left(w \frac{\partial^{2} y}{\partial z^{2}}\right) \varphi d s d y=-\int_{n} F(b) \varphi d s d y
\end{aligned}
$$

where the function $v$ depends on $t, s$, and $r$. We remak Let us set
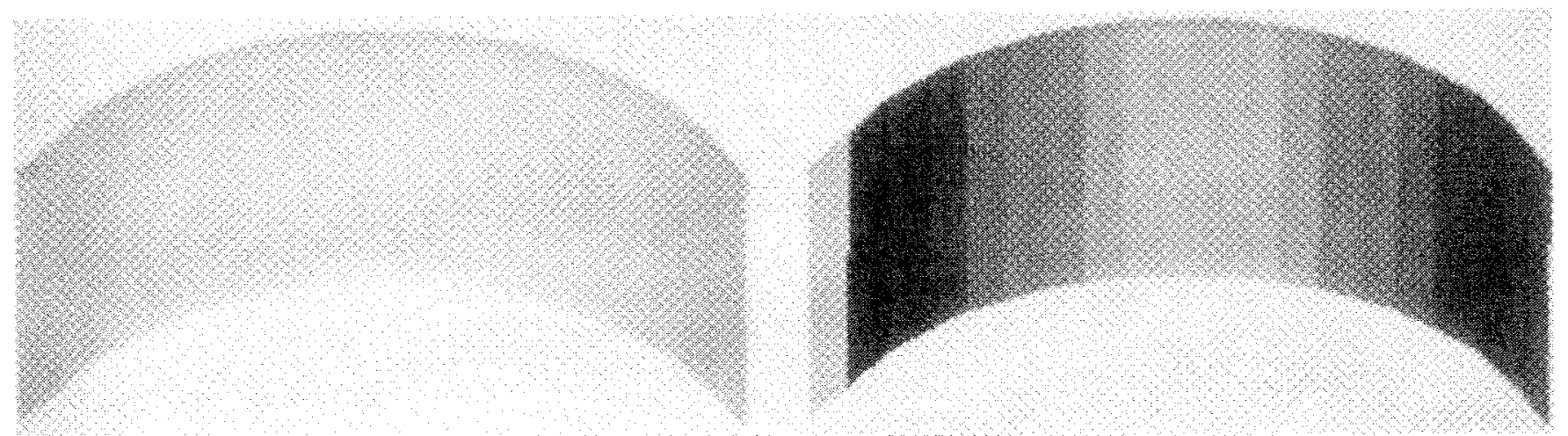

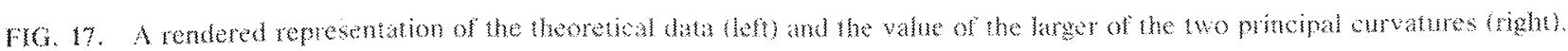
separate them for more detais see 110). Greents how mula vielos

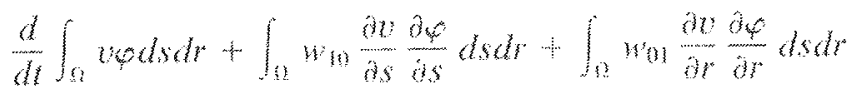

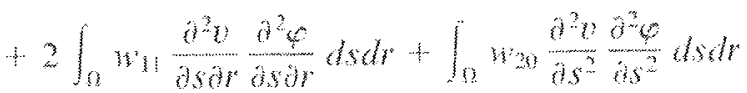

$$
\begin{aligned}
& +\int_{n} \frac{\partial^{2} y d^{2} \phi}{\partial r^{2}} \frac{\partial r^{2}}{d s d r}=-\int_{n} \nabla p(u) \phi d s d r
\end{aligned}
$$

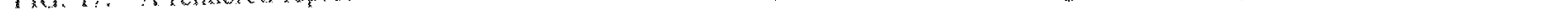




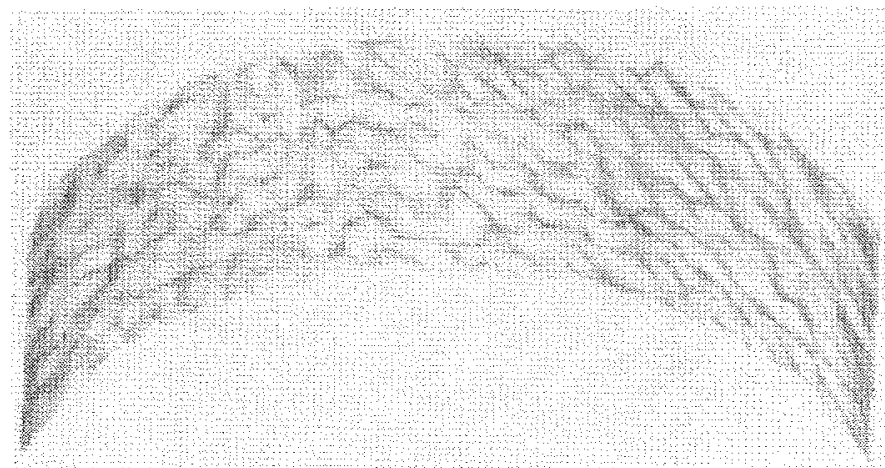

HC. 18 . A rendered representation of the nowy data $a^{2}=0.01$

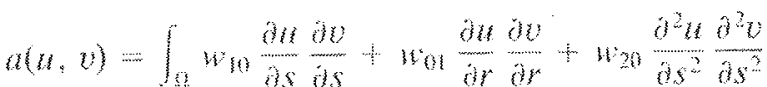

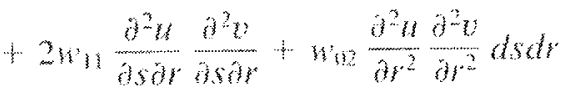

and

$$
L_{n}(u)=-\int_{0} P p(\theta) u d s d r
$$

This leads to a new formulation of the problem grven $v_{0} E$

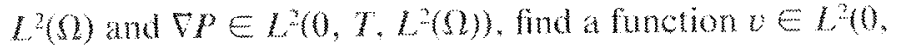
T. Hol $(\Omega) \cap\left(0,7, L^{2}(\Omega)\right)$ satifying

$$
\begin{aligned}
& \frac{d}{d t}(v(t), u)+a(v(t), w)=L(u) . \quad \forall n \in H(n) \\
& v(0)=v_{n}(s, r) \\
& w_{y} \in L(n) \text { and } w_{i}(s) \geq \alpha>0
\end{aligned}
$$

Since the variables, $3, y$, and / are independent, was can solve La. (21) in two steps. First solve the statc equation mote $y$ Hon such that

$$
u(v, u)=L(n), \quad \forall n \in H_{2}(n)
$$

Where $L_{z}$ is not supposed to deperd on $v$ me rewnd the reader that there sists a undue somion to the equation. simes the binear form $a(u, y)$ is symmetric and positive definte as long as $w_{4}>0$ ), and then solve the evolution equation (21). This yelds Ea. (13)

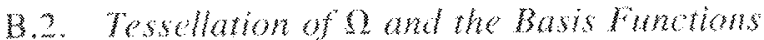

Given the numbers of discretization points in the two axes of parmetrization $N_{s}, N_{2}>1$, we sot $h_{s}=1 / N_{*}-$ 1) $h_{3}=1 /\left(N_{r}-1\right)$ and consider a mifom subdivion of a of suep size $h_{3}$ and $h_{r}$, composed of the nodes $a_{j}=\left(x_{i}\right.$. $y)=\left(i h_{s}, j h\right), 0 \leq i \leq N_{s}-1,0 \leq j \leq N_{r}-1$, Thus

$$
\begin{aligned}
& n=10,11 \times 10, \Pi=\bigcup_{i, j}^{n_{i}} K_{i, i} \\
& =\int_{n=0}^{k, \cdots, n}\left[h_{s},(1+1) h_{s}\right] \times\left[j h_{r},(j+1) h_{r}\right]
\end{aligned}
$$

Since the higher dervatives appearing in $\mathrm{Eg}$. (1) are of fourth order, the contom finte element space $V_{h}$ must

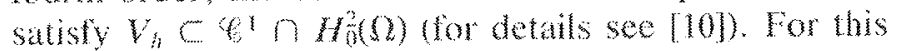
purpose the space $H_{0}(\Omega)$ is approximated wh the Bogner-Fox-Schmit dements 15,10$]$ dehned by

* The rectangles $K_{i j}$, lefined by the vertices $c, 1 \leq$ $k \leq 4$.

- The set $P_{K}$ of polynomals containing the basis funetions

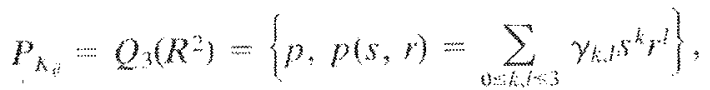

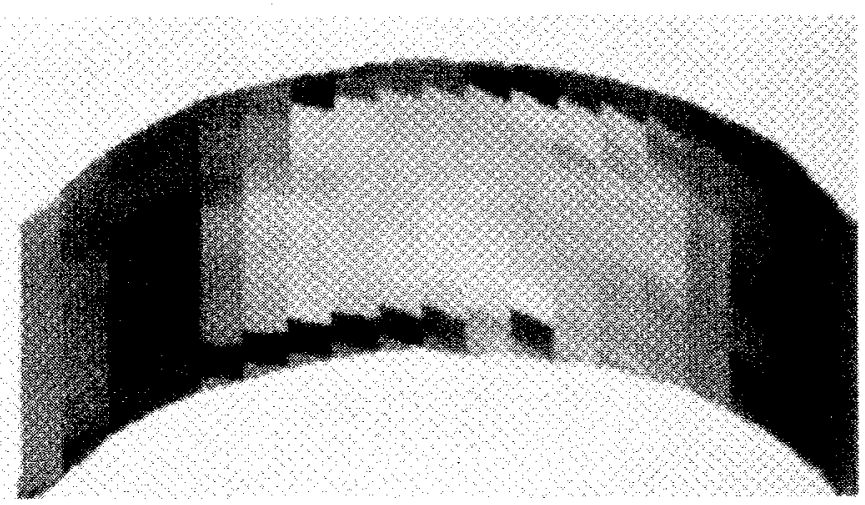

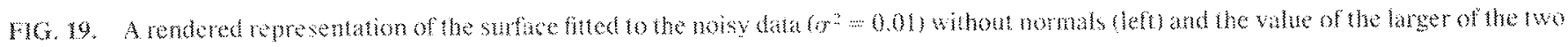
principal curvates fight). 

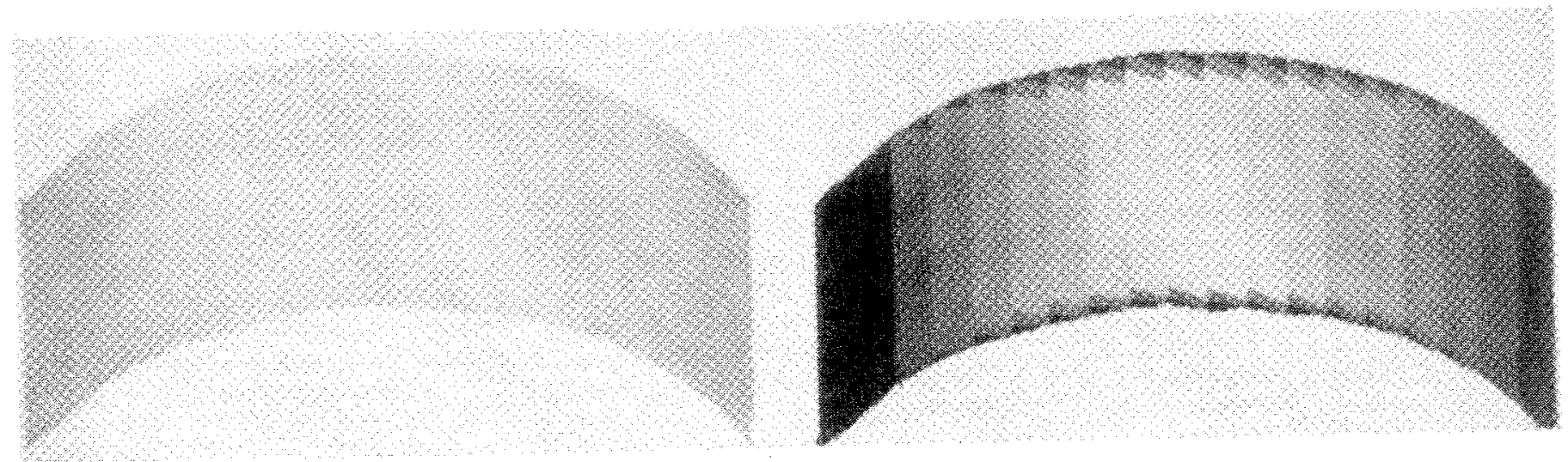

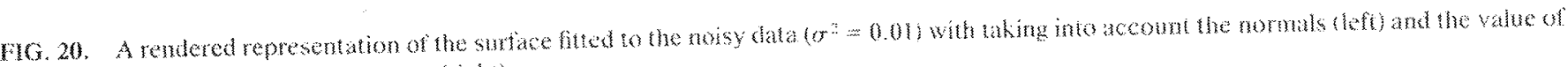
the larer of the two princinal survatures fright.

- The set $\sum_{k}=\left\{p\left(c_{k}\right), \partial p\left(c_{k}\right) / \partial s, \partial p\left(c_{k}\right) / \partial r_{3} a^{2} p\left(c_{k}\right)\right.$ $65 \mathrm{dr}, 1 \leq k \leq 4\}$, which allows us to befine in a unique way the basis functions over each rectangles $K_{i}$.

The subspace $V_{h}$ is then defined by

$$
V_{l_{3}}=\left\{y \in(n), v_{K_{i}} \in Q\left(K_{i j}\right)\right\}
$$

where $O_{k}(D$ is the vector space of the restrictions to an interval $15 R^{2}$ of the polynomials whose degree is less than $k$ for each variable, and $v_{l}$ is the restriction of the function to the subset $\%$. The basis functions of the finite element subspace $V_{h}$ are $\varphi_{i j}, \psi_{i ;}, \eta_{i}$, and $\zeta_{i j}$ and they are defned in a mique way over ach rectangle $K_{i j}$ by

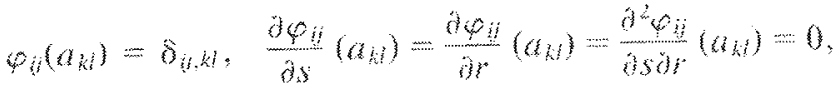

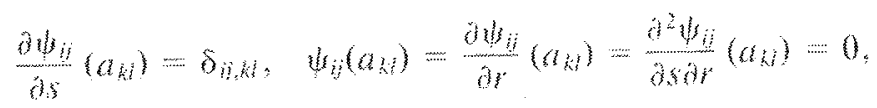

$$
\begin{aligned}
& \frac{\partial \eta_{i}}{\partial r}\left(a_{k}\right)-\delta_{i, k}, \quad \eta\left(a_{k}\right)=\frac{\partial \eta_{h}}{\partial s}\left(a_{k}\right)=\frac{\partial^{2} \eta_{n}}{\partial \sin }\left(a_{k l}\right)=0
\end{aligned}
$$

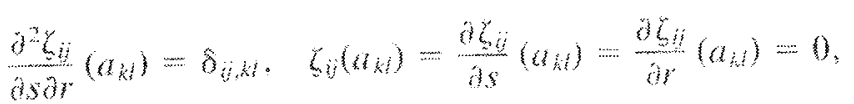

where

$$
\delta_{i n}= \begin{cases}1 & \text { if } i=k \text { and } y=1 \\ 0 & \text { ofherwae. }\end{cases}
$$

Thus $v_{3} \in V_{\text {m }}$ we have the identry

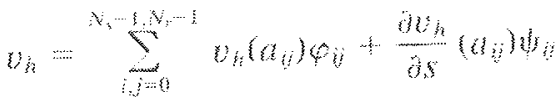

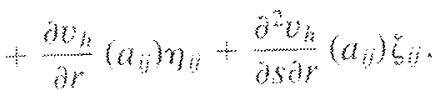

providing a conthuous representation of the solution overe the space $\Omega$.

Gquation (23) gyes the expressions of the basis tume

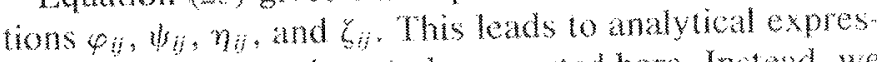
sons which are too long to be reported here. Instest, we give a gaphical representation of the low basis functions (Fig. 1$)$.

\subsection{Discrete poblem and Limea Sysem}

Rewriting the discrete problem associated whe $\mathrm{Eq}$ (22) with the basis functions gives us the equations $\forall$. $y=0_{x}, \ldots N_{5}-1, N_{,}-1$,

$$
\begin{aligned}
& a\left(b_{i}, \phi_{i}\right)=L_{n}\left(\phi_{i}\right) \\
& a\left(u_{n}, w_{i}\right)=L_{0}\left(\|_{i}\right) \\
& a\left(u_{n}, \eta_{i}\right)=L_{m}\left(\eta_{i}\right) \\
& \left.a(n), b_{n}\right)=l_{n},\left(b_{0}\right)
\end{aligned}
$$

and, using idemity $10, \forall i_{0} j=0, \ldots, N_{2}-1, N_{r}-1$

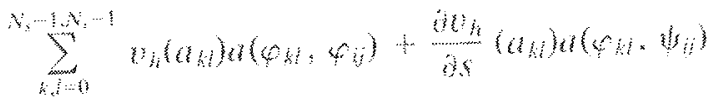

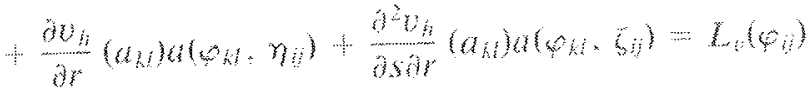

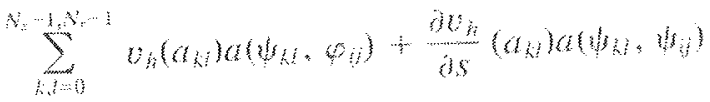

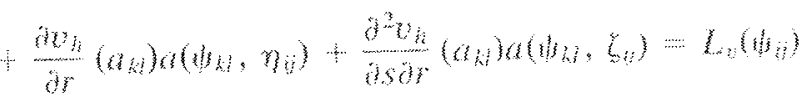

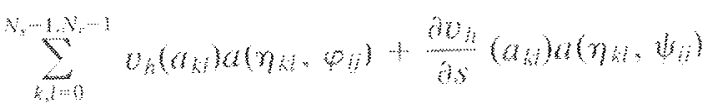

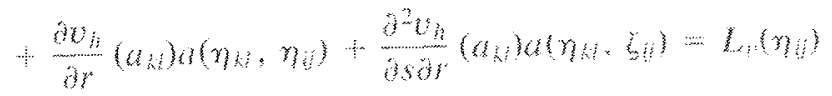




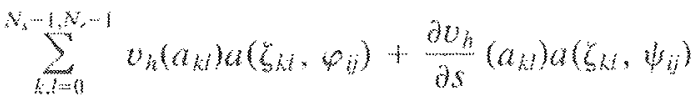

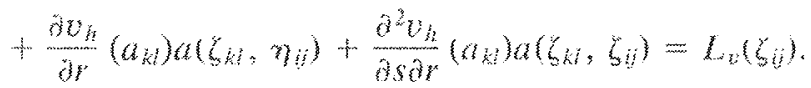

Equation $(25)$ is a linear system where the unknowns are $v_{h}\left(a_{k l}\right),\left(\partial v_{h} / \partial n\right)\left(a_{k l}\right),\left(\partial v_{h} / \partial s\right)\left(a_{k l}\right)$, and $\left(\partial v_{h} / \partial s h\right)\left(a_{k}\right)$.

Finally the solution of the discrete problem associated with (22) leads to the solution of the linear system $A$

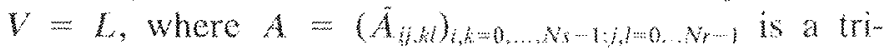
diagonal bloc array.

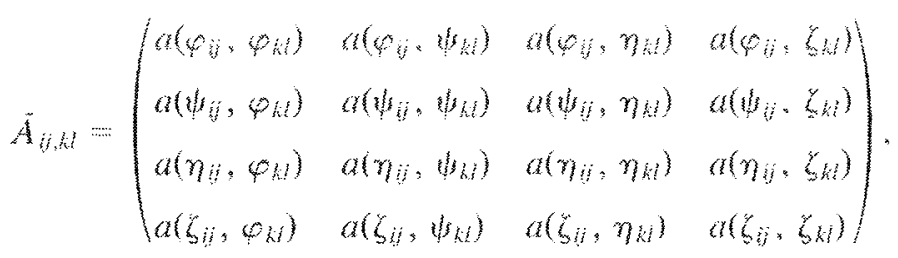

the $\hat{A}_{i, k}$ array elements depending on the elasticity and rigidity coefficients.

\section{ACKNOWUEDONONT}

This work was partially supported by Digital Equipment Corp.

\section{REFWRENCES}

1. N. Ayache, J. D. Boissonnat, E. Brune, L. Cohen, A, P. Cheze B. Geiger, O. Monga, J. M. Rocekisani. and P. Sander. Building highly structured volume representations in 3-D medical images, in Procedings, Computer Alded Radiology, Berlin, West Germany $198 \%$

2. N. Ayahe, J. D. Boissonnat, L. Cohen, B. Geiger, I. Levy Yehel, 0 . Monga, and 1 . Sander. Stens toward the automate interprear

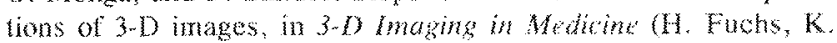
Hohne and S. Pizer, Eds.), pp. 107m120, NATO ASI Senies, Springer Venlag. New Yorkiberlm, 1990.

3. N. Ayache, 1. Cohen, and 1. Hetin. Hedical image makking in Active Vision (A. Blake and A. Yulle. Gds., Chap. 20. MTT Press. Cambridge, MA to appear.

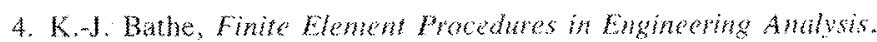
Prentice-Hall, Englewood Clffs. NJ. 1982

5. F. K. Bogner, R. L. Fox, and L. A. Schmit, The generation of interelement-compatible stifness and mass matrices by the use of interpolation formulae, in Procedings. Conference on Matrix

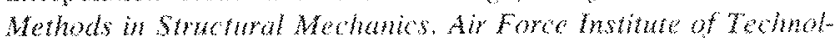
ogy. Wright Paterion A.F. Base, OH, Oct 1965.

6. J. D. Boissomat, Shape reconstruction from phanar cross-sections. Comput. Vishon Graphic: Image Process. 40.1988, 1-29,

7. G. Borgefors, Distance transformations in arbitray dimensins, Comput Vision Graphics Image Process. 2\%, 1984, 321-345.

8. M. Brady, J. Ponce, A. Yuile, and H. Asadk. Describing surfizes, in Procedings, Second lnternational Symposium on Robotics Re-

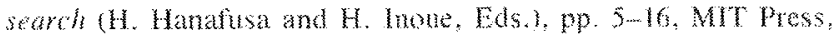
Canbridge, MA, 1985 .

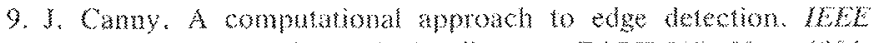

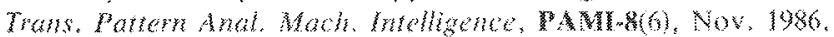
$679-698$

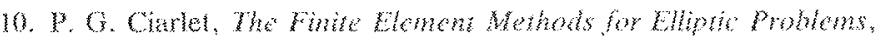
North-Holand, Amsterdam, 1987

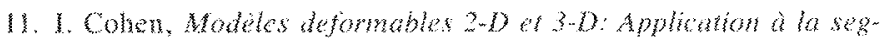

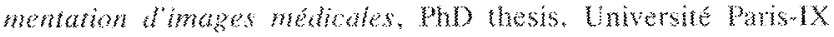
Dauphine. June 1992.

12. I. Cohen, N. Ayache, and P. Sulger, Traking points on detom

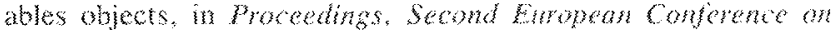

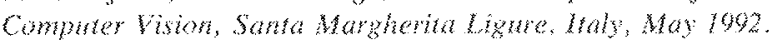

13. L. D. Cohen, on active contour molds and balloons, CFGP 1 m. age Understanding $33(3), \mathrm{Mar}, 1991,211-318$,

14. I. D. Cohen and I. Cohen, A finite element method applice to nev active contour models and 3 - D reconstuction from cross sectons,

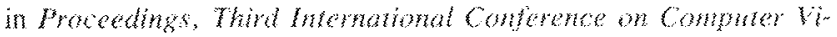

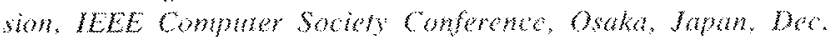
$1990, \mathrm{pp}, 597,591$.

15. L. D. Cohen and 1. Cohen, Finte Elemen Methods for Actur Conour Moulels and ballowa from 2-D to 3-D. Tech. Rep. 9124, CEREMADE. UR A. CNRS\% 49. Unverste Paris LX-Daphine. Cahiers de Mathematiques de la Decision. Nov. 1991.

16. P. E. Dandelson. Euclidean distance mapping. Compat. Vision Comphics lmage process. 14, 1980, 227-248.

1\% . M. P. do Camo. Differemial Geonety of Cumes and suteres. BrenticemHall, Englewood Clifts, NJ, 1976.

18. P. Fua and Y. O. Lecler, Model driven edge detecton, in Procent-

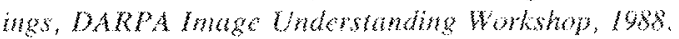

19. G. G. Cordon, Face recognition from depth and curyature, in $p_{3 y-}$

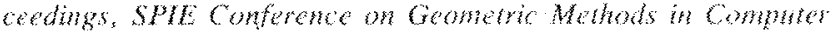
Vision, San Diego, CA, July 1991.

20. A. Gucziec and N. Ayache, Smoothing and matching of $3 \mathrm{D}$ space

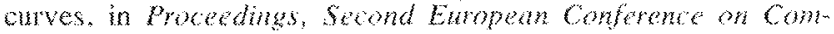

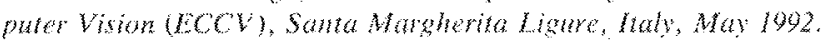

21. L. L. Herlin and N. Ayache, Features extraction and andysis meth-

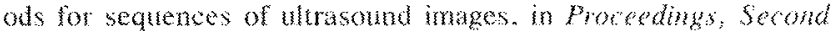
European Conference on Computa Fison (ECCY). Samu Margheria Ligute. Itaty, May 198s.

22. M. Kass, A. Witkin, and D. Terzopoulos, Snakes: Active contour models, in Procedings. Finst memationat Conference on Comwher Fision. Lonton. Jime 1987, pp. 259-268.

23. S. Lee, Visus Woniroring of Gamoma. PhD thesis, Robotics Researoh Croup, Deparment of Engineering Science, University of Oxford. 1991

24. F. Leitner and P. Cinquin, Dymmic segmentation: Detecting conplex topology 30 -object, in Prowedings, Interhational Conference sf the IELE Enginering in Medicine and Biology Suchty, Orlando. FI, Now, 1991, pp. 295-396.

25. F. Leiner, Y. Marque, S. Lxwalle, and P. Cinquin, Dynamic seg mentation: Finding the edge with snake-splines, in Procedings. Intrmational Conferester on Cumes and Sufaces. Chamanix. France. Jwhe 1990, pp. 1-4, Academic Press. San Diego. CA. 1990.

26, O. Monga, N. Ayache, and P. Sander, From voxel to curvature, in Procedings, Compuser Visin and panem Recognimon, VEEE

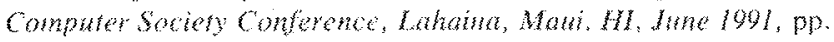
$644-649$.

27. O. Monga and R. Deriche, 3.D edge detection using recursive filtering, in Procedings, IEEE Conferente on Yaston and Punern Recogration, Sam Diewo, CA, June 1989.

28.1 . Noble. Finding comers, in Procedings, Ahey Viston Confer

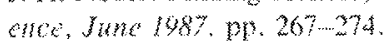


39. A. Pentand and S. Solarof, Cosed forn solutons for physically

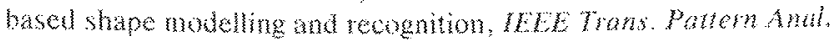

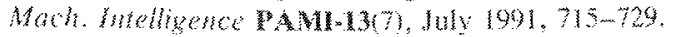

30. 1. Ponce and M. Wraty, woward a surface primal sketeh in $\mathrm{Pm}$ ceedings, WCAl. 108\%".

31. R. T. Santer and S. W Zncker. Infermingurface tace and diferen

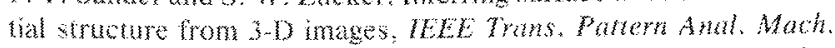
Intelligense. in press: a shortened version is available as Charting surlace structure, in Procedings, forst Europen Conference on Conputer Vision, Anthes, Apr. 23-2?

32. D. Terapoulos. The computation of visble-senface representa

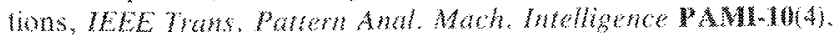
Juy $1088,47 \% 38$
3). D. Terzopoulos, 2 . Witkin, and M, Kass, Constraints on deformabe model: Recovering 3-D shape and nonrigid motion, Al J.34, $1988,91-123$.

34. D. Terzopoulos, A. Witkin, and M, Kass, Symmetry-secking models for $3-\mathrm{D}$ object reconstruction, in procedings, Firs hat

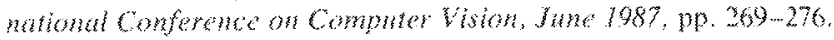

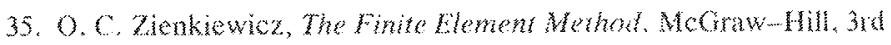
al. New York, 1977

36. S. W. Zucker and R. M. Hummel, A thre-dimensional edge opera-

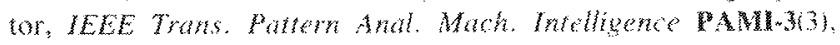
May $1981,324-331$. 